\title{
La agricultura periurbana como sostenibilidad silenciosa: desafiando el discurso del desarrollo urbano en Sogamoso, Colombia*
}

\author{
DOI: https://doi.org/10.18046/recs.i32.4149
}

\section{Peri-urban Agriculture as Quiet Sustainability: Challenging the Urban Development Discourse in Sogamoso, Colombia}

\author{
Giuseppe Feola ${ }^{* *}$ \\ Utrecht University (Utrecht, Países Bajos) \\ Jaime Alberto Suzunaga ${ }^{* * *}$ \\ Fundación Jischana Huitaca (Sogamoso, Colombia) \\ Jenny Soler ${ }^{* * * *}$ \\ Fundación Jischana Huitaca (Sogamoso, Colombia)
}

Amanda Wilson ${ }^{* * * * *}$

Investigadora independiente

\begin{abstract}
* Este artículo fue publicado originalmente con el título "Peri-urban agriculture as quiet sustainability: challenging the urban development discourse in Sogamoso, Colombia”, Journal of Rural Studies, 8oC, 1-12. https://doi.org/10.1016/j. jrurstud.2020.04.032 Traducción al español: Giuseppe Feola. Revisión: Diego Molina.

** Profesor asociado en el Instituto de Desarrollo Sostenible Copérnico, Universidad de Utrecht. Investiga el cambio socioecológico en las sociedades modernas con un enfoque empírico primario en sistemas agroalimentarios e iniciativas de base. Ha llevado a cabo investigaciones sobre medio ambiente y desarrollo, agricultura y sostenibilidad en Colombia desde 2007. Su investigación actualmente se centra en los procesos de deshacer el capitalismo por movimientos sociales agroalimentarios. Correo electrónico: g.feola@uu.nl ORCID: https://orcid.org/oooo-0003-1069-503X

*** Sociólogo de la Universidad Nacional de Colombia; ha sido docente universitario durante 12 años. Ha venido desarrollando trabajos de investigación con indígenas, campesinos y población urbana en temas relacionados con patrimonio cultural, medio ambiente y desarrollo, gestión de riesgos y cambio climático. Actualmente trabaja con procesos de soberanía y seguridad alimentaria.

**** Gestora cultural; acompaña a organizaciones sociales en temas como derechos humanos, con enfoque diferencial. Actualmente apoya la coordinación de huertas urbanas en zonas urbanas y periurbanas de Sogamoso.

***** Investigadora independiente con sede en Den Bosch (Países Bajos). Magíster en Estudios de Conflictos y Derechos Humanos de la Universidad de Utrecht. Su interés de investigación es la intersección de los estudios de movimientos sociales, paz y sostenibilidad.
\end{abstract}




\section{Cómo citar/How to cite}

Feola, Giuseppe; Suzunaga, Jaime Alberto; Soler, Jenny; Wilson, Amanda (2020). La agricultura periurbana como sostenibilidad silenciosa: desafiando el discurso del desarrollo urbano en Sogamoso, Colombia. Revista CS, 32, 279-315. https://doi.org/10.18046/recs.i32.4149 


\section{Resumen}

Este artículo representa un avance en los debates científicos y políticos sobre la agricultura periurbana (APU), al examinar el fenómeno en la ciudad de Sogamoso, Colombia. Los planificadores, desarrolladores y autoridades de este municipio han retratado explícitamente a la APU como una barrera para el desarrollo, tipificándola como una actividad atrasada, localizada, de baja tecnología y de bajo rendimiento económico que necesita dar espacio a una economía más productiva y moderna. Basado en una encuesta de 160 hogares periurbanos que se dedican a la agricultura, este estudio identifica las formas de autoabastecimiento e intercambio de alimentos (AIDE) y además caracteriza el arraigo social, las dificultades y las oportunidades implícitas en la práctica de la APU, según los perciben los agricultores periurbanos. Combinando literatura sobre la APU y sostenibilidad silenciosa, este artículo plantea una perspectiva novedosa tendiente a transformar el discurso alrededor del papel de APU y su futuro en el desarrollo sostenible urbano. Además, propone remplazar los argumentos fundamentados en métricas de productividad por una perspectiva que valore el AIDE como una práctica ambientalmente sostenible que fortalece el tejido social de las comunidades locales, contribuyendo así a su sentido de propósito y resiliencia. Este estudio tiene implicaciones no solo para Sogamoso, sino también para muchas otras ciudades de América Latina y del Sur Global, donde el papel de la APU, en relación con el desarrollo urbano sostenible, está activamente cuestionado.

\section{PALABRAS CLAVE:}

agricultura urbana, autoabastecimiento e intercambio de alimento, Foodsharing, urbanización, desarrollo sostenible, América Latina

This article advances academic and policy debates on peri-urban agriculture (PUA) by examining the phenomenon in the city of Sogamoso, Colombia. Planners, developers, and local authorities in Sogamoso have explicitly framed PUA as a barrier to development: a backwards, localized, low-tech and economically poorly performing activity that needs to make space for a more "productive" "modern" economy. Based on a survey of 160 peri-urban farming and gardening households, this study identifies PUA forms of food self-provisioning and exchange (FSPE) and further characterizes the practice's social embeddedness, barriers, and opportunities as perceived by peri-urban farmers. The article combines scholarship on PUA and 'quiet sustainability' to propose a novel perspective that could help transform the terms of discourse on the role and future of 
PUA in urban sustainable development from arguments founded in productivity metrics to the appreciation of FSPE as an environmentally sustainable practice that strengthens the social fabric of local communities, thus contributing to their sense of purpose, meaning, and resilience. This study has implications not only for Sogamoso, but also for many other cities in Latin America and the Global South, where the role of PUA in relation to sustainable urban development is being actively contested.

\section{KEYWORDS:}

Urban Agriculture, Food Self-provisioning and Exchange, Food Sharing, Urbanization, Sustainable Development, Latin America 


\section{Introducción}

Este artículo representa un avance en los debates científicos y políticos sobre la agricultura periurbana (APU). Mediante el empleo del concepto de sostenibilidad silenciosa, se busca dar visibilidad a una dimensión generalmente olvidada de este fenómeno: la existencia de prácticas normales de autoabastecimiento e intercambio de alimentos (AIDE) en espacios periurbanos. Dichas prácticas no son el resultado de iniciativas gubernamentales específicas o de organizaciones no gubernamentales con propósitos de mejoramiento medioambiental, social, económico u otro, más bien son prácticas espontáneas emanadas dentro del seno de las comunidades locales y que contribuyen a crear un sentido de propósito y a fortalecer el tejido social. Cuando se entiende como una forma de sostenibilidad silenciosa (Smith; Jehlička, 2013), la APU se puede apreciar como una práctica normal que, además de ser socialmente valiosa, desafía las concepciones productivistas y desarrollistas de esta práctica en relación con ciudades y desarrollo urbano. En consecuencia, este estudio emplea el concepto de sostenibilidad silenciosa para proponer una nueva perspectiva sobre la APU que puede ayudar a cambiar los términos del discurso de su papel y su futuro, particularmente en el Sur Global.

La agricultura urbana se puede definir como producción agrícola (de cultivos o ganado) en espacios urbanos y periurbanos la para producción de alimento u otros usos, el transporte relacionado, el procesamiento y la comercialización de los productos agrícolas y los servicios no agrícolas proporcionados por los agricultores urbanos (por ejemplo: almacenamiento de agua, agroturismo, manejo de áreas verdes y del paisaje, entre otros) (De Zeeuw, 2004). La agricultura urbana es altamente diversa; puede aparecer en diferentes formas, como huertas comunitarias, huertas caseras, jardines en la terraza, granjas urbanas, agricultura de guerrilla ${ }^{1}$, avicultura y ganadería, y granjas de acuaponía (De Zeeuw, 2004; Lin; Philpott; Jha, 2015). La agricultura urbana puede ocurrir dentro de los límites de la ciudad (intraurbana) o, como en el caso de este artículo, en los espacios que la rodean (periurbana).

La agricultura urbana ha atraído la atención de académicos, formuladores de políticas públicas y profesionales por igual como una medida potencial para abordar las necesidades alimentarias de las crecientes poblaciones urbanas y contrarrestar algunos de los efectos negativos ambientales y económicos de la urbanización

1. La agricultura de guerrilla (guerrilla gardening) es una forma de acción directa no violenta relacionada con la reforma agraria, la permacultura y el desarrollo sostenible. Los activistas ocupan una porción de tierra no cultivada o cuyos cultivos o plantas no les pertenecen, ya que formulan la necesidad de re-consideración de la forma de tenencia de tierras para reclamar el espacio utilizado de forma errónea y asignarle un nuevo propósito y utilidad (Infoagro Systems, 2012). 
(Mougeot, 2005; Orsini; Kahane; Nono-Womdim; Gianquinto, 2013; Van Veenhuizen, 2006). Los beneficios de la agricultura urbana incluyen su contribución a la seguridad alimentaria y la nutrición (Eigenbrod; Gruda, 2015; Poulsen; McNab; Clayton; Neff, 2015; Warren; Hawkesworth; Knai, 2015; Zezza; Tasciotti, 2010). En ciudades del Sur Global, donde las estimaciones indican que hasta el 6o \% de los habitantes pueden ser agricultores a tiempo completo o parcial (De Zeeuw; Dubbeling, 2009; Drechsel; Keraita, 2014), la agricultura urbana también contribuye a generar ingresos (Orsini et al., 2013; Poulsen et al., 2015; Zezza; Tasciotti, 2010). Además, la agricultura urbana puede promover conexiones entre las personas y su cultura alimentaria (Sahakian; Saloma; Erkman, 2016); la construcción de enlaces comunitarios y compromiso cívico; el empoderamiento de jóvenes, mujeres y minorías sociales, étnicas o culturales; relajación física y psicológica de las personas involucradas en esta práctica; la educación ambiental y la cura de personas con trastornos psicológicos (Orsini et al., 2013; Poulsen, 2017; Van Veenhuizen, 2006). Finalmente, la agricultura urbana puede contribuir a la gestión ambiental a través de la reutilización de residuos orgánicos urbanos, la creación de cinturones verdes, el mejoramiento del microclima urbano, la conservación del paisaje, la provisión de servicios ecosistémicos y la reducción de millas de alimentos y su huella de carbono (Drechsel; Keraita, 2014; Galluzzi; Eyzaguirre; Negri, 2010; Goldstein; Hauschild; Fernández; Birkved et al., 2017; Lin et al., 2015; Pearson; Pearson; Pearson, 2010).

Sin embargo, en el Sur Global, donde los viejos y los nuevos imperativos del desarrollo (por ejemplo, los Objetivos del Desarrollo Sostenible) son muy acuciantes, la agricultura urbana se ve a menudo como una barrera para el desarrollo. Cuando el desarrollo se define en términos de progreso tecnológico e infraestructural, productividad, crecimiento económico y conexiones culturales modernas y globales, la agricultura urbana a menudo es retratada, discursivamente y en la práctica, como una actividad atrasada, localizada, de baja tecnología y de bajo rendimiento económico - un legado del subdesarrollo pasado que debe abandonarse para abrir espacio (tierra) a una economía productiva- (Ayambire; Amponsah; Peprah; Takyi, 2019; Nadal et al., 2018). Tales actitudes son particularmente evidentes en los espacios periurbanos, los cuales son frecuentemente conceptualizados en procesos de planificación y políticas como sujetos a una inevitable transición espacial y temporal hacia la modernidad urbana (Mehta; Karpouzoglou, 2015; Tacoli, 2003).

No obstante, como zonas fronterizas, los espacios periurbanos son muy dinámicos (Marshall; Waldman; MacGregor; Mehta; Randhawa, 2009); son económicamente multifuncionales, socialmente diversos y ecológicamente complejos. En ese contexto, Pérez Martínez (2016) ha propugnado por un enfoque decididamente relacional hacia los espacios periurbanos, que rechazaría dicotomías rurales/ur- 
banas y, más bien, permitiría apreciar la multiplicidad de actores, escalas, redes y formas organizativas que caracterizan la diversidad de actividades, grupos sociales y configuraciones biofísicas que existen en los espacios periurbanos (Lerner; Eakin, 2011; Madaleno; Gurovich, 2004).

Investigadores, formuladores de políticas públicas y profesionales han tenido problemas para dar sentido a los espacios periurbanos. Representaciones de lo periurbano como espacio marginal, socialmente excluido, vulnerable y caracterizado por construcción de viviendas y economías ilegales compiten con quienes caracterizan estos paisajes como espacios verdes que albergan elementos rurales como la agricultura y la silvicultura (Marshall et al., 2009; Mougeot, 2005; Zoomers; Van Noorloos; Otsuki; Steel; Van Westen, 2017). Algunos autores han observado y discutido desajustes entre representaciones discursivas de la agricultura urbana en documentos de planificación y su realidad en el territorio (Ives; Kendal, 2013; Mackay, 2018). Asimismo, la amplia gama de actores en los espacios periurbanos hace que sea difícil saber quién se beneficia de la agricultura urbana (Contesse; Van Vliet; Lenhart, 2018); igualmente, en estos espacios se practican diversas formas de producción de alimentos que, en su mayoría y a menudo, no se reconocen ni se entienden completamente (Feola; Sahakian; Binder, 2O2O; Ives; Kendal, 2013; Mackay, 2018).

Los desafíos implícitos en el ejercicio de dar sentido a los espacios periurbanos y la AUP han evidenciado dificultades para medir sus impactos sociales, ecológicos y económicos, así como su sostenibilidad (Pearson et al., 2010). Por ejemplo, los investigadores han tenido problemas para capturar los efectos menos tangibles de esta práctica sobre las identidades culturales (Mougeot, 2005; Rodríguez-Alonso; Simón-Tenorio, 2016), así como para identificar los factores que fomentan la biodiversidad y cómo se interconectan con la diversidad cultural y la agenda política de alimentos sostenibles (Galluzzi et al., 2010; Lin et al., 2015; Mougeot, 2005).

Tanto los que se oponen como los que defienden la agricultura urbana a menudo miden sus impactos únicamente en términos de productividad material (Neilson; Rickards, 2017); estas evaluaciones limitadas a los valores monetarios han chocado con contribuciones difícilmente cuantificables como el capital simbólico del autoabastecimiento de alimentos, y su apego y reinvención de las herencias e identidades campesinas (Cantor, 2010; Méndez; Ramírez; Alzate, 2005; Sahakian et al., 2016). A su vez, desafíos en la medición de la agricultura urbana han contribuido a su invisibilidad en los documentos de planificación territorial y en el ámbito de la formulación de políticas públicas, en particular desde las perspectivas social y cultural (Feola; Suzunaga; Soler; Goodman, 2019; Ives; Kendal, 2013; Nadal et al., 2018). En resumen, los intereses y discursos desarrollistas dominantes, el carácter híbrido de los espacios periurbanos, el consecuente desafío en su gobernabilidad para lograr 
avances hacia la sostenibilidad, así como las disputas alrededor de la sostenibilidad y las evaluaciones de su impacto han contribuido a la invisibilidad de la APU, ya sea de forma deliberada o no.

Este estudio conecta los debates actuales sobre la APU, la gobernanza de espacios periurbanos y el desarrollo sostenible con el concepto de sostenibilidad silenciosa. Este concepto ha sido especialmente aplicado para denotar prácticas alimentarias duraderas que parecen reducir significativamente los impactos ambientales (De Hoop; Jehlička, 2017; Jehlička; Daněk, 2017; Smith; Jehlička, 2013; Smith; Kostelecký; Jehlička, 2015; Vávra; Daněk; Jehlička, 2018), pero que no son identificadas como ejemplos de sostenibilidad por las personas involucradas. Estas prácticas son silenciosas porque no están activamente etiquetadas o valoradas como ejemplos de desarrollo sostenible y porque tienen lugar en la geografía informal de hogares, redes sociales y relaciones. Examinadas originalmente en países exsocialistas en Europa Central y Oriental, estas prácticas han sido ignoradas o consideradas con desdén por muchos de los involucrados en la creación de políticas ambientales, como un remanente cultural embarazoso, un mecanismo económico de emergencia o una estrategia de supervivencia de los pobres (Smith; Jehlička, 2013; Pungas, 2019).

Sin embargo, se ha demostrado que prácticas de sostenibilidad silenciosas como el AIDE están muy extendidas, sobrepasan las clases sociales (Smith et al., 2015), contribuyen a la sostenibilidad ambiental (Vávra et al., 2018) y, lo más importante, fortalecen el tejido social de las comunidades locales, contribuyendo así a su sentido de propósito y resiliencia frente a la reestructuración postsocialista (Jehlička; Daněk; Vávra, 2018; Pungas, 2019; Smith; Jehlička, 2013). Es importante destacar que investigaciones anteriores sobre el concepto del AIDE y otras formas de sostenibilidad silenciosa han argumentado que estas prácticas no deben concebirse como programas para promover la sostenibilidad o como una respuesta particular a la insostenibilidad. Por el contrario, estas prácticas son la norma para una gran parte de la población en países como Polonia y República Checa. Davies et al. (2017) demostraron que existen sistemas de intercambio de alimentos en ciudades de todo el mundo y las consideraron como formas cotidianas de variadas economías comunitarias.

Debido a lo anterior, las políticas públicas deberían incorporar maneras de reconocer, proteger y promover estas prácticas ya existentes, a través de instrumentos de planificación, medidas fiscales o representación en los medios de comunicación (Jehlička et al., 2018; Smith; Jehlička, 2013) o a través de la construcción y protección de las habilidades, espacios y objetos del intercambio de alimentos² (Davies et al., 2017).

2. El término intercambio (de alimentos) se utiliza en este artículo para denotar formas de intercambio no monetario de productos que ocurren fuera del mercado. 
Esta investigación se basa en el estudio del caso ilustrativo de la ciudad de Sogamoso (Colombia), donde el contraste entre los mundos urbano y rural -una brecha crónica y extrema que, en lugar de cerrarse, se ha ido ampliando de manera general en el país (Parra-Peña; Ordóñez; Acosta, 2012)- se puede observar en todas sus contradicciones en el espacio periurbano (Feola, 2017; Feola et al., 2019). En Sogamoso, la APU ha sido explícitamente enmarcada por planificadores, promotores inmobiliarios y autoridades locales como una barrera al progreso económico (Feola et al., 2019); sin embargo, existen imaginarios urbanos alternativos que reclaman un papel para la práctica en el desarrollo sostenible de la ciudad.

En este contexto, este artículo busca responder las siguientes preguntas de investigación: ¿cómo se interconectan la agricultura periurbana y las prácticas de sostenibilidad silenciosa en la ciudad de Sogamoso?, ¿cómo pueden esas interconexiones ayudar a refinar o avanzar en las teorizaciones de la agricultura periurbana y la sostenibilidad silenciosa?, y ¿cuáles son las implicaciones de tales interconexiones para el desarrollo urbano en la ciudad de Sogamoso y otras ciudades colombianas?

Este trabajo representa un avance en los debates científicos y políticos sobre la APU, a través de la caracterización de esta práctica en Sogamoso, la identificación de sus conexiones con el AIDE y la exploración de su arraigo social, dificultades y oportunidades tal como los perciben los agricultores periurbanos 3 . En última instancia, al emplear el concepto de sostenibilidad silenciosa, se sugiere una nueva perspectiva sobre la APU, la cual podría contribuir a cambiar los términos del discurso sobre su papel y su futuro no solo en Sogamoso, sino también, posiblemente, en muchas otras ciudades de América Latina y el Sur Global, donde el papel de la APU en relación con el desarrollo urbano está intensamente en disputa.

\section{Metodología}

\section{Recolección y análisis de datos}

Los datos para este estudio fueron recolectados a través de una encuesta a 173 agricultores e igual número de hogares dedicados a la agricultura y horticultura, seleccionados de acuerdo con un diseño de muestreo no aleatorio estratificado en ocho sectores periurbanos de Sogamoso (Figura 1). Los sectores seleccionados, que se encuentran dentro de la frontera del municipio, se caracterizan por grandes porciones de tierra

3. En este artículo, utilizamos el término agricultor (farmer, en inglés) para designar tanto a los productores de alimentos con fines comerciales como a los productores de alimentos para fines no comerciales. Este último tipo de productores a menudo se menciona como horticultor (gardener, en inglés) en la literatura. 
designadas como de uso mixto (rural-urbano) del suelo o para expansión urbana. Sin embargo, los sectores difieren con respecto a las actividades económicas dominantes.

La agricultura comercial es una importante actividad económica en Siatame y La Manga, mientras que la industria y la minería son sectores económicos dominantes en Pantanito y Ramada. Moniquirá, y los sectores Universitario, Manitas y Vanegas se caracterizan por usos mixtos de la tierra y la presencia de agricultura y horticultura; sin embargo, estos sectores del sur han estado en la mira de promotores inmobiliarios urbanos para la construcción de complejos residenciales, en contraste con lo que ocurre en Moniquirá, donde la urbanización ha ocurrido en menor medida y principalmente guiada por una reducida inversión familiar en la construcción de segundas residencias.

La encuesta se realizó entre septiembre de 2017 y abril 2018. Todos los sectores están clasificados como estrato socioeconómico 1 (muy bajo) o 2 (bajo), según el Departamento Administrativo Nacional de Estadística (DANE), aunque nuevas propiedades residenciales para estratos socioeconómicos hasta el nivel 4 (medio) se han desarrollado, particularmente en los sectores periurbanos sur (Universitario, Manitas y Vanegas). El cuestionario fue estructurado en secciones temáticas que cubrían la información sociodemográfica básica del hogar, características de la vivienda y de la tierra, producción agrícola (dos secciones separadas para productos vegetales y ganaderos, respectivamente), opiniones sobre la APU, dificultades y oportunidades para la APU y datos económicos del hogar. Se aplicaron procedimientos éticos estándar y consentimiento informado previo, donde las identidades de todos los participantes permanecen confidenciales. Los entrevistadores fueron capacitados antes de administrar el cuestionario en el campo.

Los datos se analizaron utilizando el software IBM SPSS para elaborar estadísticas descriptivas. El análisis implicó una exploración inicial del conjunto de datos para identificar características importantes de la muestra y obtener una descripción general de la APU en Sogamoso, lo que fue seguido por un análisis más detallado de la APU basado en la identificación de patrones dentro de la muestra. Específicamente, según las tipologías de agricultura urbana propuestas anteriormente por Cantor (2010), cuatro tipos de agricultura y de hogares que se dedican a la horticultura se identificaron con base en dos variables: 1) el porcentaje de ingresos recibidos por cuenta de la agricultura sobre el total del ingreso del hogar, y 2) el porcentaje de los miembros del hogar que trabajan en la agricultura (como actividad primaria o secundaria). Se planteó la hipótesis de que los hogares de diferentes tipos se involucrarían con la APU de manera diferente, así como enfrentarían dificultades distintas y preverían oportunidades diferentes debido a niveles desiguales de dependencia y dedicación a la agricultura en espacios periurbanos. 
FIGURA 1 Mapa de Sogamoso (Colombia)

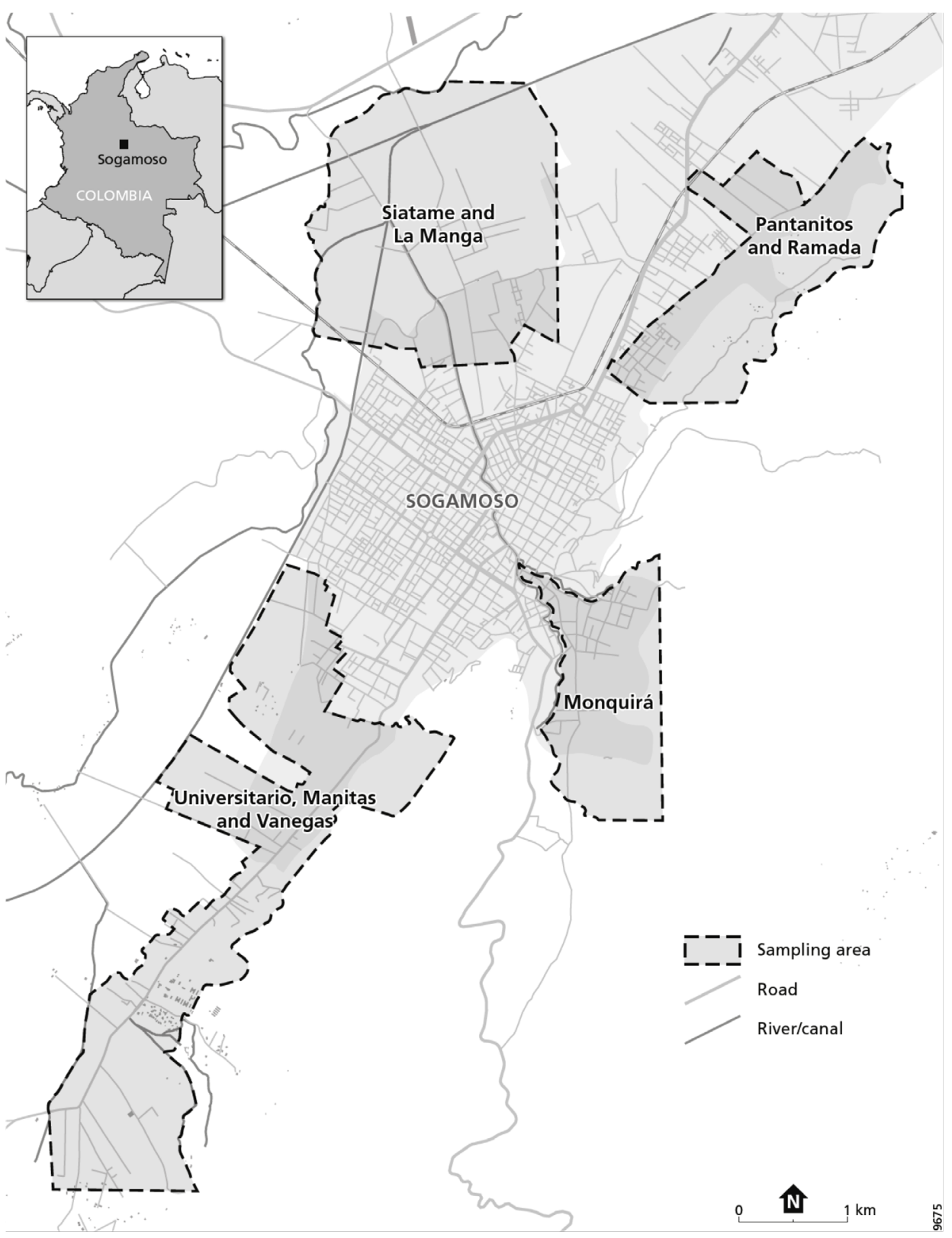


El tipo A $(\mathrm{N}=32)$ comprende hogares de agricultores comerciales para quienes la dependencia del ingreso en la agricultura es igual a $75 \%$ o más, independientemente del porcentaje de miembros del hogar que trabajan en la agricultura. El tipo $\mathrm{B}(\mathrm{N}=38)$ se compone de hogares para los cuales la dependencia del ingreso por la agricultura es más de o \% pero menos de $75 \%$, y más de $50 \%$ de los miembros están involucrados en la agricultura. El tipo $\mathrm{C}(\mathrm{N}=54)$ representa hogares para los cuales la dependencia del ingreso por la agricultura es más de o \% pero menos de $75 \%$; sin embargo, menos de $50 \%$ de los miembros están involucrados en la agricultura. Finalmente, el tipo $\mathrm{D}(\mathrm{N}=36)$ comprende hogares para los cuales el ingreso no depende de la agricultura, independientemente del porcentaje de miembros del hogar que participan en dicha actividad. Trece casos fueron excluidos del análisis porque los datos con respecto a una o ambas de las dos variables mencionadas anteriormente no estaban disponibles.

Este estudio es parte de un proyecto de investigación más amplio enfocado en agricultura periurbana, en el que se realizaron 38 entrevistas semiestructuradas a informantes clave y la encuesta mencionada anteriormente. Los informantes clave comprendían miembros de la sociedad civil (organizaciones no gubernamentales en ámbito social, cultural o ambiental; periodistas), funcionarios públicos, autoridades locales y miembros de los sectores de la construcción, educación (universidades, empresas sociales) y agrícola (agricultores de subsistencia, agricultores comerciales, líderes de organizaciones de agricultores, minoristas). Las entrevistas se estructuraron en cuatro secciones que se centraron en los siguientes temas: 1) agricultura, soberanía alimentaria y desarrollo sostenible en Sogamoso; 2) el Acuerdo de Paz con las Fuerzas Armadas Revolucionarias de Colombia (FARC) y el impacto esperado en Sogamoso de la delineada reforma del desarrollo rural;3) gobernanza agrícola en los espacios periurbanos de la ciudad; y 4) visiones de líneas políticas y otras posibilidades para apoyar y ampliar los beneficios de la APU. Algunos de los resultados del proyecto de investigación más amplio se proporcionan aquí como información contextual para este artículo.

\section{Caso de estudio: conflictos sobre el uso del suelo en Sogamoso (Colombia)}

Situada en la Cordillera Oriental de los Andes, aproximadamente a $2600 \mathrm{msnm}$, la ciudad de Sogamoso es la capital de la provincia de Sugamuxi en el departamento de Boyacá y tiene una población de 120 ooo habitantes (Departamento Administrativo Nacional de Estadística, 2018). La economía de este municipio se basa principalmen- 
te en la industria, la minería, el comercio, la prestación de servicios y la agricultura ${ }^{4}$. La agricultura campesina y de pequeña escala en la región ha enfrentado una crisis en las últimas dos décadas, debido a la baja productividad, la competencia de los mercados nacionales e internacionales, la emigración de generaciones más jóvenes y la falta de apoyo del gobierno (Feola, 2017; Feola; Agudelo-Vanegas; Contesse-Bamón, 2015). El declive socioeconómico de las zonas rurales es indicado por el índice de pobreza multidimensional, que es casi tres veces mayor en las zonas rurales que en las urbanas de Sugamuxi 5 . Como resultado de este desequilibrio, se ha observado una migración sustancial de áreas rurales a áreas urbanas y periurbanas, y se espera que esta continúe en el futuro.

Con solo 4748 habitantes por kilómetro cuadrado, Sogamoso se encuentra entre las ciudades menos densamente pobladas del país, con al menos 100 ooo habitantes (Departamento Nacional de Planeación [DNP], 2016). Sin embargo, se ha registrado un déficit habitacional de alrededor de 4000 unidades (DNP, 2016), caracterizado como un déficit cuantitativo y cualitativo de aproximadamente 2300 y 1700 unidades, respectivamente (Alcaldía de Sogamoso, 2016). Solo en el año 2017, el municipio de Sogamoso aprobó 427 licencias de construcción residencial, la mayoría de las cuales eran para vivienda en la periferia urbana (Cámara de Comercio de Sogamoso, 2017).

El desarrollo urbano es operado en gran medida por empresas locales y regionales, las cuales se dirigen a las clases media y media alta que desean mudarse fuera del centro de la ciudad para disfrutar de un ambiente menos congestionado y más verde en viviendas de alto nivel, a menudo en conjuntos cerrados (Feola et al., 2019). El expansionismo urbano también es promovido por personas particulares, tanto locales como de las grandes ciudades colombianas (las cuales a menudo tienen raíces familiares en Sogamoso), quienes construyen casas familiares no para venta, sino para ellos mismos, como residencias primarias o secundarias. Tanto los constructores inmobiliarios como los compradores individuales (que incluyen los miembros más jóvenes de familias antiguamente dedicadas a la agricultura) influyen en la designación de tierras a través de canales informales o como parte de los procesos

4. Además del expansionismo urbano y la agricultura, que compiten por la tierra en prácticamente todos los sectores periurbanos de Sogamoso, partes de los espacios periurbanos son también disputados por intereses mineros (carbón, arcilla, fósforo, césped y arenas) y esfuerzos para conservar el ecosistema de páramo de alta montaña (Feola et al., 2019). Sin embargo, el principal conflicto de tierras en los sectores urbanos examinados en este artículo es entre agricultura y expansionismo urbano; en consecuencia, el enfoque aquí es sobre el conflicto entre esos dos usos del suelo.

5. En 2013, este índice era de 61,6\% vs. 24,5\% (Departamento Nacional de Planeación, 2013, como se citó en Alcaldía de Sogamoso, 2016). 
participativos que sirven de insumo en la creación del documento de planeación territorial (Plan de Ordenamiento Territorial) ${ }^{6}$.

La expansión de las áreas urbanas en espacios periurbanos ${ }^{7}$ ha ocurrido en gran medida a expensas de la agricultura, que sigue siendo practicada en los espacios periurbanos de Sogamoso, donde el suelo es muy fértil, en lotes baldíos entre desarrollos residenciales y en solares y patios. Por ejemplo, además de las granjas comerciales que operan dentro del perímetro urbano, el municipio de Sogamoso dio información de más de 630 hogares que se dedican a la autoproducción de alimentos (Alcaldía de Sogamoso, 2016). Las autoridades locales han documentado repetidos casos de contaminación de vegetales producidos por granjas en el sector periurbano occidental debido al uso de aguas residuales contaminadas (Alcaldía de Sogamoso, 2016); este problema es bien conocido entre los gerentes de supermercados locales, que, de ser posible, evitan abastecer sus tiendas con verduras de esas granjas (gerente de supermercado, comunicación personal, 10.08.2018).

Aprobado en 2016, el último Plan de Ordenamiento Territorial (POT) formalizó la expansión de la ciudad en áreas de desarrollo residencial no autorizadas, zonas que anteriormente eran designadas como rurales. Este cambio en el uso del suelo también respondió a las presiones locales para aumentar el valor económico de la tierra y permitir una mayor construcción de vivienda. Igualmente, el cambio en el POT apuntó a responder a un número significativo de disputas legales relacionadas con asignaciones del uso del suelo y conflictos sociales derivados de usos residenciales en áreas designadas como no residenciales en la periferia urbana (Alcaldía de Sogamoso, 2013; 2016). Sin embargo, los cambios no necesariamente reflejan usos reales del suelo, dado que la mayoría de las áreas para expansión urbana todavía están ocupadas por actividades rurales como la agricultura. Un funcionario de la oficina del desarrollo local describió así la situación:

en estos sectores (...) [hay] un conflicto grande, a mi modo de ver, porque digamos que en esos territorios hay lista desde hace mucho tiempo la zona residencial pero simultáneamente estaba ahí ubicada la subsistencia de las personas, bien fuera agricultura bien fuera minería (...), igual sucedía hacia el sector sur. Hay un montón de construcciones ya con licencia de los servicios públicos con absolutamente todo, pero desde el POT

6. La ley 388 de 1997 creó un sistema de gobernanza para la planificación municipal de ordenamiento territorial con el objetivo de identificar acciones estratégicas para el desarrollo socioeconómico y el manejo de recursos naturales (Arias-Arbeláez; Vargas, 2010).

7. Estos son espacios dentro de la frontera municipal que fueron designados para expansión urbana, uso mixto (rural-urbano) o uso rural. 
anterior allá ya no se puede construir nada; eran áreas de expansión agrícola, entonces hay ese conflicto. (comunicación personal, 02.08.2017)

Los cambios en el POT reflejaron más bien las aspiraciones de los planificadores, constructores y residentes de ampliar el área que se designa como urbana para el desarrollo de la ciudad. Las empresas de construcción se han involucrado activamente en influir sobre el proceso de zonificación urbana, incluso recurriendo a disputas legales para expandir la zonificación urbana a través del POT en algunas áreas de la periferia urbana del sur de Sogamoso. Además, una coalición informal de planificadores, constructores y autoridades locales, entre otros actores, ha tendido a proyectar espacios periurbanos como vacíos y desprovistos de actividades productivas o de algún valor. El espacio periurbano de la ciudad ha sido representado como un espacio improductivo, marginal, atrasado, estático, informal, premoderno, listo para su urbanización y de este modo ser desarrollado: "incorporamos 745 hectáreas de suelo de expansión y suelo urbano para darle dinamismo al territorio"8 (concejal municipal, comunicación personal, 03.08.2017); “teníamos muy buena gente para trabajar [en agricultura]. Desafortunadamente (...) al campesino nunca le fue bien (...) el campesino para mí no quiso crecer y se quedó (...) una cultura muy tenaz y desafortunada de nuestro campesino"9 (planificador, comunicación personal, 27.07.2017); "cualquier terreno en Sogamoso y donde usted quiera se vuelve más rentable produciendo casas que sembrando" 10 (constructor, comunicación personal, 04.08.2017);

Hay unos casos que sí le gusta a la gente por lo menos sembrar para su consumo (...), pero debería haber más más siembra (...) para utilizar más los suelos. Están utilizando para ovejas, para vaca, y mucho está ahí abandonado; no se está produciendo como debería ser. (Periodista, comunicación personal, 01.08.2017)

Las periferias de las ciudades [como la] de Sogamoso son muy feas; son cordones de hambre cordones de miseria cuando no están organizados. Yo hago lo contrario. Yo quise poner unos punticos así bonitos para no desarrollar miseria, para no desarrollar casas de lona, casas horribles (...) lo que hay que poner es casitas bonitas, para que por lo menos esas casitas bonitas generen desarrollo, generan recursos. Una finca; esto era una finca, todo esto era una finca. Pagaba 650 700 [pesos] de impuesto predial. Hoy día está pagando más de 6 ooo oooo (...) desarrollamos una parte constructiva, pusimos
8. Cursivas propias.
9. Cursivas propias.
10. Cursivas propias. 
a valer la tierra, (...) sacrificamos una zona donde teníamos 10 vacas 11 vacas no había más en toda la finca ${ }^{11}$. (Constructor, comunicación personal, 04.08.2017)

Aquellos discursos desarrollistas no son compartidos por todos los actores sociales de Sogamoso. Varios miembros de la comunidad científica local y de la sociedad civil, (investigadores universitarios y docentes, organizaciones no gubernamentales, grupos de ciudadanos) cuestionan el expansionismo urbano e identifican este fenómeno como el principal impulsor de la fragmentación del tejido medioambiental, productivo y social, y la pérdida cultural asociada con la desaparición de la agricultura en las áreas alrededor de la ciudad. Esto incluye la pérdida de tradiciones culinarias locales, conocimiento y habilidades agrícolas, autonomía alimentaria y alimentos saludables producidos biológicamente. Del mismo modo, varios informantes clave comentaron sobre del deterioro ambiental como consecuencia de la urbanización, la pérdida de suelo fértil causada por desarrollos residenciales e insuficiencias infraestructurales (Feola et al., 2019). En otras palabras, para estos observadores, la APU no es una barrera para el desarrollo, sino una práctica cuya pérdida señala el empobrecimiento cultural y la degradación ambiental asociada con el desarrollo urbano moderno: "Somos una región que puede (...) retomar su vocación agrícola" (miembro de un grupo de caminantes, comunicación personal, 24.07.2017);

\footnotetext{
Pues para mí este espacio es el lugar donde nacimos, donde hemos vivido; es nuestra tierra, es el sitio que queremos para seguir viviendo, y queremos mejorarlo para conseguir lo que necesitamos para vivir, como nuestro alimento, nuestra vivienda; (...) de qué forma lo cuidamos, cómo vamos a mejorarlo para no dañar el medio ambiente (...). Cómo podemos vivir con la naturaleza en armonía, y cómo [la] conservamos; entonces es importante para nosotros o para mí este lugar, este sitio, este suelo. (Artesano y agricultor, comunicación personal, 27.07.2017)
}

Estos actores de la sociedad civil comparten imaginarios urbanos de desarrollo sostenible para Sogamoso que son inseparables del renacimiento de la APU y de los espacios periurbanos. Desde su perspectiva, el espacio periurbano no está vacío, sino lleno de significado cultural y medioambiental, y el valor de las actividades realizadas allí no es medido según criterios económicos, sino en términos de pertenencia social, afiliación y apego. En contraste con el discurso desarrollista de progreso, estos imaginarios enfatizan en la necesidad y la oportunidad de recuperar tradiciones premodernas, particularmente cultivos indígenas, prácticas de cultivación y de riego, así como la autonomía, dignidad y agencia del campesinado y de la ciudadanía.

11. Cursivas propias. 
Además de las disputas discursivas, el espacio periurbano en Sogamoso también se caracteriza por conflictos sobre el uso del suelo. Estudios anteriores han asociado dichos conflictos en este espacio con los problemas de incoherencia entre políticas públicas y problemáticas de gobernanza (Feola et al., 2019). El primero incluye un panorama político fragmentado y políticas contradictorias dentro y entre los sectores (por ejemplo, agricultura, comercio, vivienda, desarrollo industrial), así como en múltiples niveles que van desde lo local a lo nacional. Esta situación genera incertidumbre normativa, una sensación de vulnerabilidad para poblaciones y la frustración acerca del funcionamiento de las autoridades municipales. A su vez, la incertidumbre justifica aún más las estrategias informales de la ciudadanía y grupos sociales para defender sus intereses o perseguir sus objetivos a través de sistemas de gobernanza formal e informal. Las problemáticas de gobernanza incluyen la escasa capacidad técnica y la falta de datos confiables sobre el estado de la ciudad, la corrupción de funcionarios públicos que anteponen sus intereses particulares sobre los del bien común, la falta de liderazgo estratégico y una deficiente cultura participativa (Feola et al., 2019).

La injusticia resultante de la incoherencia entre políticas y las problemáticas de gobernanza es evidente, con campesinos, agricultores urbanos y otros ciudadanos marginalizados perdiendo tierra, ingresos y acceso a recursos en un espacio periurbano que está funcionalmente configurado para los actores colectivos o individuales mejor conectados con esferas de poder y, al mismo tiempo, más fuertes política y financieramente (Feola et al., 2019).

\section{Resultados}

\section{Caracterización de la agricultura periurbana}

Entre los cuatro tipos de hogares agrícolas identificados en este estudio, el tipo A se caracterizó por las proporciones más altas de miembros involucrados en la agricultura como ocupación única o principal. En contraste, los tipos B, C y D presentaron mayores proporciones de miembros del hogar para quienes la agricultura era una ocupación secundaria (Cuadro 1).

Mientras que los tipos A y B tendían a ubicarse en dos sectores periurbanos (Siatame y La Manga), este estudio encontró agricultores periurbanos en los cuatro sectores seleccionados (Cuadro 1). Los miembros de los hogares en los tipos C y D, para los cuales el ingreso dependía menos o nada de la agricultura y, por lo tanto, era probable que estuvieran empleados en otros sectores económicos, generalmente 
CUADRO 1 Caracterización de cuatro tipos de hogares dedicados a la agricultura en Sogamoso*

\section{Variables}

Tipo A $\mid$ Tipo B $\mid$ Tipo C $\mid$ Tipo D $\mid$ Tipo A

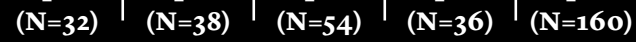

\begin{tabular}{lcccccc}
$\begin{array}{l}\text { Tamaño promedio } \\
\text { del hogar** }\end{array}$ & $\begin{array}{c}3,81 \\
(1,76)\end{array}$ & $\begin{array}{c}3,11 \\
(1,78)\end{array}$ & $\begin{array}{c}4,07 \\
(1,73)\end{array}$ & $\begin{array}{c}3,61 \\
(1,70)\end{array}$ & $\begin{array}{c}3,68 \\
(1,74)\end{array}$ \\
\hline $\begin{array}{l}\text { Tamaño promedio } \\
\text { / mediano de }\end{array}$ & & & & & \\
$\begin{array}{l}\text { tierras agrícolas } \\
\text { en metros } \\
\text { cuadrados }^{* *}\end{array}$ & Cultivos y hierbas & $4214 /$ & $580 / 200$ & $1531 / 168$ & $468 / 100$ & $2620 /$ \\
& 1500 & $(1218)$ & $(3031)$ & $(1238)$ & $\begin{array}{c}200 \\
(12056)\end{array}$
\end{tabular}

cuadrados $^{* *}$

\begin{tabular}{|c|c|c|c|c|c|c|}
\hline \multirow{3}{*}{$\begin{array}{l}\text { Número de } \\
\text { encuestados } \\
\text { por ubicación }\end{array}$} & $\begin{array}{l}\text { Pantanitos } \\
\text { y Ramada }\end{array}$ & $2(6,3)$ & $3(7,9)$ & $11(20,4)$ & $5(13,2)$ & $21(13,1)$ \\
\hline & Monquirá & $6(18,8)$ & $11(28,9)$ & $13(24,1)$ & $17(44,7)$ & $47(29,4)$ \\
\hline & $\begin{array}{l}\text { Universitario, Manitas y } \\
\text { Vanegas }\end{array}$ & $6(18,8)$ & $6(15,8)$ & $18(33,3)$ & $12(31,6)$ & $42(26,3)$ \\
\hline
\end{tabular}

Proporción promedio de miembros del hogar para quienes la agricultura es la única ocupa$\begin{array}{lllll}0,25 & 0,07 & 0,11 & 0,10 & 0,12\end{array}$ ción $^{* *}$

$\begin{array}{llll}(0,34) & (0,24) \quad(0,17) & (0,26) \quad(0,25)\end{array}$

Proporción promedio

Número de encuestados por ocupación de miembros del hogar para quienes la agricultura es la ocupación principal $^{\text {** }}$

$\begin{array}{ccccc}0,23 & 0,17 & 0,9 & 0,07 & 0,12 \\ (0,36) & (0,34) & (0,16) & (0,20) & (0,26)\end{array}$

Proporción promedio de miembros del hogar para quienes la agricultura es la $\begin{array}{ccccc}0,7 & 0,56 & 0,20 & 0,36 & 0,31 \\ (0,18) & (0,36) & (0,23) & (0,29) & (0,33)\end{array}$ ocupación secundaria**

\begin{tabular}{|c|c|c|c|c|c|c|}
\hline \multirow{4}{*}{$\begin{array}{l}\text { Número de } \\
\text { hogares por nivel } \\
\text { educativo más } \\
\text { alto alcanzado } \\
\text { por cualquier } \\
\text { miembro del } \\
\text { hogar }\end{array}$} & $\begin{array}{l}\text { Sin escolaridad o } \\
\text { escuela primaria }\end{array}$ & $7(21,9)$ & $11(28,9)$ & $12(22,3)$ & $10(27,8)$ & $\begin{array}{c}40 \\
(25,0)\end{array}$ \\
\hline & Escuela secundaria & $18(56,3)$ & $11(28,9)$ & $18(33,3)$ & $10(27,8)$ & $57(35,6)$ \\
\hline & Escuela técnica & $3(9,4)$ & $11(28,9)$ & $8(14,8)$ & $7(19,4)$ & $29(18,1)$ \\
\hline & $\begin{array}{l}\text { Escuela universitaria o } \\
\text { posgrado }\end{array}$ & $3(9,4)$ & $5(13,2)$ & $15(2$ & $9(25,0)$ & $32(20,0)$ \\
\hline \multirow{2}{*}{$\begin{array}{l}\text { Número de } \\
\text { hogares por } \\
\text { tenencia de la } \\
\text { tierra agrícola }\end{array}$} & Propia & $17(53,1)$ & 29 & $42(77,8)$ & $21(58,3)$ & $\begin{array}{c}109 \\
(68,1)\end{array}$ \\
\hline & En arriendo & A & $8(21,1)$ & $10(18,5)$ & $7(19,4)$ & $39(24,4)$ \\
\hline \multirow{2}{*}{$\begin{array}{l}\text { Número de } \\
\text { hogares por forma } \\
\text { de explotación de } \\
\text { la tierra }\end{array}$} & Individual & $18(56,3)$ & $31(81,6)$ & $35(64,8)$ & $18(50,0)$ & $\begin{array}{c}102 \\
(63,7)\end{array}$ \\
\hline & En compañía & $12(37,5)$ & $4(10,5)$ & $18(33,3)$ & $12(33,3)$ & $46(28,7)$ \\
\hline
\end{tabular}


Número de

hogares que usan productos químicos en la agricultura

Número de hogares que siembran especies nativas

$$
21(65,6) \quad 9(23,7) \quad 14(25,9) \quad 8(22,2) \quad 52(32,5)
$$

$12(37,5) \quad 13(34,2) \quad \begin{gathered}24 \\ (44,4)\end{gathered} \quad 14(38,9) \quad 63(39,4)$

${ }^{*}$ Los porcentajes se calcularon dentro de los grupos y se presentan entre paréntesis, a menos que se indique lo contrario. Los valores faltantes y las modalidades con bajas frecuencias no se presentan en esta tabla.

${ }^{* *}$ Desviación estándar entre paréntesis.

Fuente: elaboración propia.

habían obtenido calificaciones educativas más altas que las de los tipos A y B (Cuadro 1). En general, estas cifras no solo indican la prevalencia de la producción agrícola como actividad secundaria o complementaria, sino que también sugieren una amplia difusión geográfica y social de la APU en Sogamoso.

La mayoría de los agricultores entrevistados explotaban sus tierras individualmente en lugar de asociarse con otros agricultores. Los agricultores en los tipos B y $\mathrm{C}$ tendían, con mayor frecuencia, a ser propietarios de la tierra, mientras que los agricultores en el tipo A eran más frecuentemente arrendatarios (Cuadro 1).

En los cuatro tipos de hogares se cultivaba una amplia gama de plantas. Estos cultivos incluían verduras (acelga, ají, apio, borraja, brócoli, calabaza, coliflor, papa, espinaca, frijol, habas, lechuga, maíz, nabo, rábano, repollo, tomate, pepino, zanahoria), frutas (manzana, pera, higo, ciruela, maracuyá, durazno, feijoa, lulo, mora, papayuela, tomate de árbol, saúco), tabaco y hierbas aromáticas y medicinales (perejil, caléndula, cilantro, guascas, limonaria, manzanilla, poleo, menta, melisa, rue, entre otras). Los hogares tipo A producían una gama inferior de cultivos, mientras que los tipos B, C y D producían más variedad de cultivos en promedio, pero también mostraban mayores variaciones en el número de cultivos dentro de los grupos. Con respecto a los animales, $33,5 \%$ de los hogares encuestados tenía aves de corral, $26 \%$ tenía ganado, $11,4 \%$ tenía ovejas o cabras, y $4 \%$ tenía conejos. Una pequeña minoría de hogares en los cuatro tipos producía huevos, leche, lana, queso o carne.

Los hogares solían vender todo o parte de su producto a un conjunto de compradores que incluían intermediarios, mayoristas, minoristas, supermercados, cooperativas de mercados locales y consumidores finales (Cuadro 2).

Las prácticas del AIDE evidenciaron que 83,1 \% de los hogares encuestados (respuestas válidas) consumían al menos parte de los alimentos de producción propia (ya 
\begin{tabular}{l|l} 
CUADRO 2 & Venta de productos por destino*
\end{tabular}

\begin{tabular}{|c|c|c|c|}
\hline Comprador & $\begin{array}{c}\text { Productos de } \\
\text { origen animal }\end{array}$ & Cultivos & Total \\
\hline Acopiador local & 20 & 22 & 42 \\
\hline Cooperativa & $\mathrm{O}$ & 2 & 2 \\
\hline $\begin{array}{l}\text { Comerciante } \\
\text { mayorista }\end{array}$ & 3 & 24 & 27 \\
\hline Comerciante minorista & 5 & 12 & 17 \\
\hline Plaza de mercado local & 6 & 38 & 44 \\
\hline Supermercado & 2 & $\mathrm{O}$ & 2 \\
\hline Consumidor final & 34 & 69 & 103 \\
\hline
\end{tabular}

${ }^{*}$ Las cifras son el número de veces que se mencionó a un comprador. Múltiples respuestas fueron posibles.

sea productos animales o vegetales/frutas/hierbas). El porcentaje de autoconsumo era mayor entre los hogares dedicados únicamente a la producción de vegetales/ frutas/hierbas. Los porcentajes eran muy altos en todos los tipos de hogares; sin embargo, fueron más altos entre los tipos de hogar B, C y D que en los del tipo A, los cuales se dedicaban más a la producción de alimentos con fines comerciales (Cuadro 3). La proporción mediana de los alimentos consumidos dentro del hogar con respecto al total de alimentos producidos oscila entre 0,5 y 1 entre los cuatro tipos. Los hogares de los tipos $\mathrm{C}$ y $\mathrm{D}$ mostraron las tasas más altas de autoconsumo. De este modo, mientras que $38 \%$ de los hogares que presentaron autoconsumo de todos los alimentos por ellos producidos pertenecían al tipo D, 32,1\% pertenecían al tipo C (Cuadro 3).

Los resultados de las preguntas sobre prácticas de intercambio de alimentos arrojaron que $26,3 \%$ de los encuestados solían intercambiar productos de cultivo propio. A pesar de ser una minoría, esta cifra es un porcentaje sustancial de la muestra. Asimismo, en el caso del AIDE, las tasas de intercambio de alimentos eran más altas para los tipos de hogar B, C y D que para el tipo A (Cuadro 3). En general, los porcentajes de hogares que se dedicaban al intercambio de alimentos o al autoconsumo de verduras/frutas/hierbas eran más altos que los que se dedicaban al intercambio de alimentos o al autoconsumo de productos de origen animal (Cuadro 3). La tasa media de alimentos intercambiados en comparación con el total de alimentos producidos 
CUADRO 3 Autoabastecimiento e intercambio de alimentos en Sogamoso ${ }^{*}$

\begin{tabular}{|c|c|c|c|c|c|}
\hline Variables & $\begin{array}{l}\text { Tipo A } \\
(\mathbf{N}=32)\end{array}$ & $\begin{array}{l}\text { Tipo B } \\
(\mathbf{N}=\mathbf{3 8})\end{array}$ & $\begin{array}{l}\text { Tipo C } \\
(\mathbf{N}=54)\end{array}$ & $\begin{array}{l}\text { Tipo D } \\
(\mathbf{N}=36)\end{array}$ & $\begin{array}{c}\text { Tipo A } \\
(\mathbf{N}=160)\end{array}$ \\
\hline $\begin{array}{l}\text { Número de hogares que consumieron al } \\
\text { menos parte de la producción propia de } \\
\text { animales** }\end{array}$ & $8(25,0)$ & $21(55,3)$ & $16(29,6)$ & $5(13,9)$ & $50(31,3)$ \\
\hline $\begin{array}{l}\text { Número de hogares que consumieron al } \\
\text { menos parte de la producción propia de } \\
\text { vegetales, frutas o hierbas }\end{array}$ & $23(71,9)$ & $31(81,6)$ & $\begin{array}{c}40 \\
(74,1)\end{array}$ & $26(72,2)$ & $\begin{array}{c}120 \\
(75,0)\end{array}$ \\
\hline $\begin{array}{l}\text { Número de hogares que consumieron al } \\
\text { menos parte de la producción propia de } \\
\text { animal y la producción propia de vegetales, } \\
\text { frutas o hierbas }\end{array}$ & $23(71,9)$ & $36(94,7)$ & $46(85,2)$ & $28(77,8)$ & $133(83,1)$ \\
\hline $\begin{array}{l}\text { Número de hogares que intercambiaron } \\
\text { animales o producción propia de animales }\end{array}$ & $\mathrm{o}(\mathrm{o}, \mathrm{o})$ & $3(7,9)$ & $5(9,3)$ & $4(11,1)$ & $12(7,5)$ \\
\hline $\begin{array}{l}\text { Número de hogares que intercambiaron } \\
\text { verduras, frutas o hierbas propias }\end{array}$ & $4(12,5)$ & $10(26,3)$ & $15(27,8)$ & $11(30,6)$ & $\begin{array}{c}40 \\
(25,0)\end{array}$ \\
\hline $\begin{array}{l}\text { Número de hogares que intercambiaron } \\
\text { animales o producción propia de animales, o } \\
\text { vegetales, frutas o hierbas propias }\end{array}$ & $4(12,5)$ & $10(26,3)$ & $16(29,6)$ & $12(33,3)$ & $42(26,3)$ \\
\hline \multicolumn{6}{|c|}{$\begin{array}{l}{ }^{*} \text { Los porcentajes se calcularon dentro de los grupos y presentados entre paréntesis, a menos que se indique } \\
\text { lo contrario. Los valores faltantes no se presentan en esta tabla. }\end{array}$} \\
\hline
\end{tabular}

varió entre 25 y 33 \% para la mayoría de los tipos de productos. El tipo de hogar A mostró la tasa más baja de intercambio de alimentos, mientras que los tipos $\mathrm{B}, \mathrm{C}$ y D tendieron a intercambiar proporciones más altas de sus productos (Cuadro 3 ).

\section{Agricultura en el espacio socioecológico periurbano: dificultades y oportunidades}

Los agricultores de los cuatro tipos de hogares identificados en este estudio tenían una percepción general muy positiva del papel de la APU en Sogamoso y destacaron particularmente el papel de la agricultura periurbana en el suministro de alimentos saludables a la ciudad (Cuadro 4). En relación con este punto, los tipos B, C y D, que tenían tasas de participación más altas en AIDE (Cuadro 3), tendían a usar menos insumos químicos que el tipo A (Cuadro 1). 
\begin{tabular}{l|l} 
CUADRO 4 & Dimensión social de la agricultura periurbana en Sogamoso*
\end{tabular}

\section{Afirmaciones}

\section{\begin{tabular}{l|l|l|l|r} 
Tipo A & Tipo B & Tipo C & Tipo D & Total
\end{tabular} \\ $(\mathbf{N}=32) \quad(N=38) \quad(N=54) \quad(N=36) \mid(N=160)$}

\begin{tabular}{|c|c|c|c|c|c|c|}
\hline \multirow{3}{*}{$\begin{array}{l}\text { Las instituciones de } \\
\text { Sogamoso ven bien a } \\
\text { los agricultores de este } \\
\text { sector }\end{array}$} & De acuerdo & $3(9,4)$ & $9(23,7)$ & $16(29,6)$ & $7(19,4)$ & $35(21,9)$ \\
\hline & $\begin{array}{l}\text { Ni de acuerdo } \\
\text { ni en desacuerdo }\end{array}$ & $4(12,5)$ & $7(18,4)$ & $14(25,9)$ & $9(25,0)$ & $34(21,3)$ \\
\hline & En desacuerdo & $23(71,9)$ & $21(55,3)$ & $23(42,6)$ & $15(41,7)$ & $82(51,2)$ \\
\hline \multirow{3}{*}{$\begin{array}{l}\text { Los consumidores } \\
\text { no ven bien a los } \\
\text { agricultores de este } \\
\text { sector }\end{array}$} & De acuerdo & $14(43,8)$ & $12(31,6)$ & $17(31,5)$ & $6(16,7)$ & $\begin{array}{c}49 \\
(30,6)\end{array}$ \\
\hline & $\begin{array}{l}\text { Ni de acuerdo } \\
\text { ni en desacuerdo }\end{array}$ & $6(18,8)$ & $8(21,1)$ & $14(25,9)$ & $7(19,4)$ & $35(21,9)$ \\
\hline & En desacuerdo & $7(21,9)$ & $16(42,1)$ & $21(38,9)$ & $19(52,8)$ & $63(39,4)$ \\
\hline \multirow{3}{*}{$\begin{array}{l}\text { Los agricultores en } \\
\text { este sector tienen una } \\
\text { función importante } \\
\text { para la seguridad } \\
\text { alimentaria de } \\
\text { Sogamoso }\end{array}$} & De acuerdo & $27(84,4)$ & $33(86,8)$ & $\begin{array}{c}40 \\
(74,1)\end{array}$ & $24(66,7)$ & $\begin{array}{c}124 \\
(77,5)\end{array}$ \\
\hline & $\begin{array}{l}\text { Ni de acuerdo } \\
\text { ni en desacuerdo }\end{array}$ & $2(6,3)$ & $1(2,6)$ & $6(11,1)$ & $2(5,6)$ & $11(6,9)$ \\
\hline & En desacuerdo & $1(3,1)$ & $3(7,9)$ & $7(13,0)$ & $7(19,4)$ & $18(11,3)$ \\
\hline \multirow{3}{*}{$\begin{array}{l}\text { La actividad } \\
\text { agropecuaria en } \\
\text { este sector facilita el } \\
\text { acceso al alimento en } \\
\text { Sogamoso }\end{array}$} & De acuerdo & $26(81,3)$ & $33(86,8)$ & $44(81,5)$ & $25(69,4)$ & $\begin{array}{c}128 \\
(80,0)\end{array}$ \\
\hline & $\begin{array}{l}\text { Ni de acuerdo } \\
\text { ni en desacuerdo }\end{array}$ & $4(12,5)$ & $2(5,3)$ & $7(13,0)$ & $5(13,9)$ & $18(11,3)$ \\
\hline & En desacuerdo & $1(3,1)$ & $3(7,9)$ & $1(1,9)$ & $6(16,7)$ & $11(6,9)$ \\
\hline \multirow{3}{*}{$\begin{array}{l}\text { Los jóvenes ven } \\
\text { bien su futuro como } \\
\text { agricultores en este } \\
\text { sector de Sogamoso }\end{array}$} & De acuerdo & $6(18,8)$ & $4(10,5)$ & $4(7,4)$ & $6(16,7)$ & $20(12,5)$ \\
\hline & $\begin{array}{l}\text { Ni de acuerdo } \\
\text { ni en desacuerdo }\end{array}$ & $3(9,4)$ & $2(5,3)$ & $13(24,1)$ & $2(5,6)$ & $20(12,5)$ \\
\hline & En desacuerdo & $21(65,6)$ & $32(84,2)$ & $35(64,8)$ & $24(66,7)$ & $\begin{array}{c}112 \\
(70,0)\end{array}$ \\
\hline \multirow{3}{*}{$\begin{array}{l}\text { La actividad } \\
\text { agropecuaria en este } \\
\text { sector no proporciona } \\
\text { alimento sano }\end{array}$} & De acuerdo & & & $10(18,5)$ & ,2) & $30(18,8)$ \\
\hline & $\begin{array}{l}\text { Ni de acuerdo } \\
\text { ni en desacuerdo }\end{array}$ & $7(21,9)$ & $8(21,1)$ & $7(13,0)$ & $2(5,6)$ & $24(15,0)$ \\
\hline & En desacuerdo & $18(56,3)$ & $24(63,2)$ & $35(64,8)$ & $26(72,2)$ & $\begin{array}{c}103 \\
(64,4)\end{array}$ \\
\hline \multirow{3}{*}{$\begin{array}{l}\text { La actividad } \\
\text { agropecuaria en este } \\
\text { sector no permite el } \\
\text { bienestar de nosotros } \\
\text { los agricultores }\end{array}$} & De acuerdo & $5(15,6)$ & $9(24,3)$ & $12(22,2)$ & $6(16,7)$ & $32(20,1)$ \\
\hline & $\begin{array}{l}\text { Ni de acuerdo } \\
\text { ni en desacuerdo }\end{array}$ & $5(15,6)$ & $5(13,5)$ & $15(27,8)$ & $6(16,7)$ & $31(19,5)$ \\
\hline & En desacuerdo & $20(62,5)$ & $22(59,5)$ & $26(48,1)$ & $22(61,1)$ & $\begin{array}{c}90 \\
(56,6)\end{array}$ \\
\hline
\end{tabular}




\begin{tabular}{|c|c|c|c|c|c|c|}
\hline \multirow{3}{*}{$\begin{array}{l}\text { La actividad } \\
\text { agropecuaria en este } \\
\text { sector favorece mi } \\
\text { sentido de pertenencia } \\
\text { con la comunidad al } \\
\text { territorio }\end{array}$} & De acuerdo & $23(71,9)$ & $29(76,3)$ & $45(83,3)$ & $30(83,3)$ & $\begin{array}{c}127 \\
(79,4)\end{array}$ \\
\hline & $\begin{array}{l}\text { Ni de acuerdo } \\
\text { ni en desacuerdo }\end{array}$ & $4(12,5)$ & $2(5,3)$ & $5(9,3)$ & $1(2,8)$ & $12(7,5)$ \\
\hline & En desacuerdo & $3(9,4)$ & $6(15,8)$ & $2(3,7)$ & $4(11,1)$ & $15(9,4)$ \\
\hline \multirow{3}{*}{$\begin{array}{l}\text { La actividad } \\
\text { agropecuaria en este } \\
\text { sector fortalece mi } \\
\text { tejido social }\end{array}$} & De acuerdo & $25(78,1)$ & $33(86,8)$ & $41(75,9)$ & $25(69,4)$ & $\begin{array}{c}124 \\
(77,5)\end{array}$ \\
\hline & $\begin{array}{l}\text { Ni de acuerdo } \\
\text { ni en desacuerdo }\end{array}$ & $3(9,4)$ & $3(7,9)$ & $6(11,1)$ & $2(5,6)$ & $14(8,8)$ \\
\hline & En desacuerdo & $2(6,3)$ & $2(5,3)$ & $6(11,1)$ & $6(16,7)$ & $16(10,0)$ \\
\hline \multirow{3}{*}{$\begin{array}{l}\text { La actividad } \\
\text { agropecuaria en este } \\
\text { sector no facilita el } \\
\text { intercambio de saberes }\end{array}$} & De acuerdo & $7(21,9)$ & $8(21,1)$ & $16(29,6)$ & $13(36,1)$ & $44(27,5)$ \\
\hline & $\begin{array}{l}\text { Ni de acuerdo } \\
\text { ni en desacuerdo }\end{array}$ & $3(9,4)$ & $1(2,6)$ & $13(24,1)$ & $4(11,1)$ & $21(13,1)$ \\
\hline & En desacuerdo & $21(65,6)$ & $29(76,3)$ & $\begin{array}{c}24 \\
(44,4)\end{array}$ & $15(41,7)$ & $89(55,6)$ \\
\hline \multirow{3}{*}{$\begin{array}{l}\text { La actividad } \\
\text { agropecuaria en } \\
\text { este sector potencia } \\
\text { mis habilidades y } \\
\text { conocimiento }\end{array}$} & De acuerdo & $21(65,6)$ & $33(86,8)$ & $44(81,5)$ & $20(55,6)$ & $\begin{array}{c}118 \\
(73,8)\end{array}$ \\
\hline & $\begin{array}{l}\text { Ni de acuerdo } \\
\text { ni en desacuerdo }\end{array}$ & $6(18,8)$ & $2(5,3)$ & $6(11,1)$ & $10(27,8)$ & $24(15,0)$ \\
\hline & En desacuerdo & $4(12,5)$ & $2(70)$ & $3(5,6)$ & $3(8,3)$ & $13(8,1)$ \\
\hline \multirow{3}{*}{$\begin{array}{l}\text { La actividad } \\
\text { agropecuaria en este } \\
\text { sector garantiza la } \\
\text { calidad de mi paisaje }\end{array}$} & De acuerdo & $24(75,0)$ & $33(86,8)$ & $47(87,0)$ & $31(86,1)$ & $\begin{array}{c}135 \\
(84,4)\end{array}$ \\
\hline & $\begin{array}{l}\text { Ni de acuerdo } \\
\text { ni en desacuerdo }\end{array}$ & $5(15,6)$ & $3(7,9)$ & $4(7,4)$ & $2(5,6)$ & $14(8,8)$ \\
\hline & En desacuerdo & $2(6,3)$ & $2(5,3)$ & $2(3,7)$ & $2(5,6)$ & $8(5,0)$ \\
\hline \multirow{3}{*}{$\begin{array}{l}\text { Mi terreno está } \\
\text { protegido y reconocido } \\
\text { por la planificación } \\
\text { territorial }\end{array}$} & De acuerdo & $7(53,1)$ & $21(55,3)$ & $33(61,1)$ & $15(41,7)$ & $86(53,8)$ \\
\hline & $\begin{array}{l}\text { Ni de acuerdo } \\
\text { ni en desacuerdo }\end{array}$ & $5(15,6)$ & $4(10,5)$ & $2(3,7)$ & $4(11,1)$ & $15(9,4)$ \\
\hline & En desac & $9(28,1)$ & $10(26,3)$ & $17(31,5)$ & $9(25,0)$ & $45(28,1)$ \\
\hline \multirow{3}{*}{$\begin{array}{l}\text { No me preocupa } \\
\text { perder la tenencia de } \\
\text { la tierra }\end{array}$} & De acuerdo & $5(15,6)$ & $7(18,4)$ & $8(14,8)$ & $6(16,7)$ & $26(16,3)$ \\
\hline & $\begin{array}{l}\text { Ni de acuerdo } \\
\text { ni en desacuerdo }\end{array}$ & $2(6,3)$ & $2(5,3)$ & $3(5,6)$ & $1(2,8)$ & $8(5,0)$ \\
\hline & En desacuerdo & $24(75,0)$ & $28(73,7)$ & $42(77,8)$ & $24(66,7)$ & $\begin{array}{c}118 \\
(73,8)\end{array}$ \\
\hline \multirow{3}{*}{$\begin{array}{l}\text { Mi terreno está bajo } \\
\text { presiones para otros } \\
\text { usos }\end{array}$} & De acuerdo & $12(37,5)$ & $12(31,6)$ & $11(20,4)$ & $9(25,0)$ & $44(27,5)$ \\
\hline & $\begin{array}{l}\text { Ni de acuerdo ni } \\
\text { en desacuerdo }\end{array}$ & $1(3,1)$ & $6(15,8)$ & $7(13,0)$ & $3(8,3)$ & $17(10,6)$ \\
\hline & En desacuerdo & $18(56,3)$ & $18(47,4)$ & $34(63,0)$ & $19(52,8)$ & $89(55,6)$ \\
\hline
\end{tabular}


En general, los encuestados de los cuatro tipos coincidieron en afirmar que la agricultura fomenta el sentido de comunidad; sin embargo, los tipos C y D expresaron los grados más altos en relación con la contribución positiva de la APU. Del mismo modo, los agricultores compartieron la opinión de que la APU contribuye a un paisaje de calidad y refuerza los lazos sociales, mientras mejora las habilidades y conocimientos agrícolas (Cuadro 4).

A pesar de su percepción positiva alrededor del papel de la APU en Sogamoso, los encuestados de los cuatro tipos de hogares tenían una posición pesimista sobre el futuro de la misma en la ciudad. Los agricultores se mostraron preocupados por el reconocimiento formal y la protección de sus tierras agrícolas en el proceso de planificación, y muchos temían perder la posesión de sus tierras (Cuadro 4). Los que sentían más presión sobre su tierra debido a posibles cambios en el uso del suelo eran los hogares tipo A y B (Cuadro 4), los cuales se dedicaban a una agricultura más comercial y trabajaban con mayor frecuencia en tierras alquiladas (Cuadro 1).

Los hogares del tipo A, los cuales estaban ubicados principalmente en un sector que estuvo asociado con la contaminación del agua en el pasado, percibieron con relativa frecuencia una reputación negativa de la APU entre las autoridades locales y los consumidores (Cuadro 4). Los encuestados de hogares del tipo A también informaron más frecuentemente que enfrentaban dificultades económicas (por ejemplo, falta de financiamiento para los agricultores, costos de producción, pequeños márgenes de ganancia de la producción agrícola) que los encuestados de hogares del tipo B, C o D. Los agricultores en los cuatro tipos de hogares se enfrentaron a dificultades técnicas (de cultivo) como la mala calidad del suelo, deficiente acceso al recurso hídrico o a los pesticidas (Cuadro 5).

Del mismo modo, los encuestados a menudo identificaron un bajo apoyo gubernamental y una precaria asistencia institucional como una dificultad. En efecto, los participantes indicaron niveles muy bajos de asistencia técnica $(8,1 \%$ recibió asistencia técnica en el último año) y crédito para la agricultura (10,4\% obtuvo crédito para la producción agrícola en el último año). Sin embargo, los hogares de los tipos $\mathrm{C}$ y D indicaron, con una frecuencia relativamente mayor, haber recibido asistencia técnica, lo que podría explicarse por los programas de actualización que ofrece el Servicio Nacional de Aprendizaje (SENA), una institución de capacitación técnica que, al estar abierta al público, por lo general recibe a ciudadanos interesados en la agricultura. Además, los encuestados de hogares del tipo A mostraron una mayor frecuencia en relación con la obtención de créditos (Cuadro 4). Sin embargo, los muchos casos de valores no disponibles (missing values) para esta pregunta pueden indicar un pesimismo generalizado sobre el futuro de la APU en Sogamoso, que contrasta con las oportunidades identificadas por una minoría de encuestados. 
CUADRO 5 Dificultades y oportunidades de la agricultura periurbana en Sogamoso ${ }^{*}$

\begin{tabular}{|c|c|c|c|c|c|c|}
\hline & Variables & $\begin{array}{l}\text { Tipo A } \\
(\mathbf{N}=32)\end{array}$ & $\begin{array}{l}\text { Tipo B } \\
(\mathbf{N}=38)\end{array}$ & $\begin{array}{l}\text { Tipo C } \\
(\mathbf{N}=54)\end{array}$ & $\begin{array}{l}\text { Tipo D } \\
(\mathbf{N}=36)\end{array}$ & $\begin{array}{c}\text { Total } \\
(\mathrm{N}=160)\end{array}$ \\
\hline \multirow{5}{*}{ Dificultades } & $\begin{array}{l}\text { Dificultades técnicas } \\
\text { (cultivación) }\end{array}$ & 24 & 35 & 36 & 26 & 88 \\
\hline & $\begin{array}{l}\text { Falta de apoyo } \\
\text { institucional }\end{array}$ & 13 & 11 & 40 & 17 & 81 \\
\hline & $\begin{array}{l}\text { Falta de conocimiento de } \\
\text { la agricultura y prejuicios }\end{array}$ & 4 & 9 & 3 & 8 & 24 \\
\hline & $\begin{array}{l}\text { Envejecimiento de la } \\
\text { población de agricultores }\end{array}$ & $\mathrm{O}$ & 8 & 3 & $\mathrm{O}$ & 11 \\
\hline & Dificultades económicas & 21 & 18 & 29 & 13 & 81 \\
\hline \multirow{5}{*}{ Oportunidades } & $\begin{array}{l}\text { Mejora del medio ambien- } \\
\text { te y la calidad de la tierra }\end{array}$ & 1 & 7 & 10 & 10 & 28 \\
\hline & Seguridad alimentaria & 3 & 12 & 16 & 20 & 51 \\
\hline & $\begin{array}{l}\text { Accesibilidad (proximidad } \\
\text { a la ciudad) }\end{array}$ & 23 & 23 & 17 & 7 & 70 \\
\hline & Beneficios económicos & 14 & 16 & 32 & 11 & 73 \\
\hline & Mejor calidad de vida & 4 & 11 & 6 & 4 & 25 \\
\hline
\end{tabular}

${ }^{*}$ Las cifras son el número de veces que se mencionó un tipo de barrera/oportunidad. Múltiples respuestas fueron posibles.

Frente a estas dificultades, los encuestados en los cuatro tipos de hogares identificaron de forma diversa distintas oportunidades ofrecidas por la APU y motivaciones para dedicarse a ella (Cuadro 5). Por ejemplo, algunos agricultores vieron la APU como una oportunidad económica, a menudo como un complemento a otras fuentes de ingreso, como un medio para lograr una mayor estabilidad financiera. La accesibilidad de la APU en la ciudad fue mencionada a menudo, particularmente por los encuestados de los tipos de hogar A y B, que producían con mayor frecuencia para el mercado. La seguridad alimentaria (por ejemplo, acceso a alimentos, acceso a alimentos saludables) y la mejora de la calidad ambiental también se consideraron como oportunidades para desarrollar la APU, particularmente entre los hogares del tipo $\mathrm{D}$, lo que puede indicar una fuerte orientación hacia la calidad ambiental entre estos participantes (Cuadro 5). 


\section{Discusión}

En esta sección se analiza la contribución empírica de este estudio al debate actual alrededor de la APU en Sogamoso. Igualmente, se analiza su aporte teórico a una literatura más amplia sobre este tipo de agricultura y la sostenibilidad silenciosa. Asimismo, se presentan las implicaciones de este estudio en el marco de políticas públicas tendientes a proteger y promover APU y AIDE en espacios periurbanos en Colombia.

\section{Agricultura periurbana en Sogamoso}

Este estudio ha caracterizado la diversidad de la APU en la ciudad de Sogamoso (Colombia). Se estudiaron hogares periurbanos en este municipio que dependían de la agricultura en distintos grados para su subsistencia. Junto con los hogares agrícolas que producían principalmente para abastecer al mercado, se tuvo también una mayor proporción de hogares para los cuales la agricultura no era ni la ocupación principal ni la principal fuente de ingresos. Se mostró cómo en Sogamoso se distinguen diferentes tipos de APU en relación con factores como tamaño y tenencia de la tierra, niveles de producción, orientación al mercado, prácticas agrícolas (por ejemplo, uso de químicos, uso de recursos hídricos), formas de explotación de la tierra (individual, colectiva), y las dificultades sufridas distinguen diferentes tipos de APU (Cuadros 1-5). Por lo tanto, este estudio sugiere que, como en otras ciudades del mundo (De Zeeuw, 2004; Lin et al., 2015; Mackay, 2018), la APU en Sogamoso no es en absoluto un fenómeno homogéneo. Tal diversidad tiene importantes implicaciones prácticas, que se analizarán más adelante.

Este estudio encontró evidencia sustancial del AIDE en relación con la APU en Sogamoso. Aunque no todos los agricultores periurbanos se involucraron en el AIDE en la misma medida y forma, tales prácticas estaban muy extendidas en todos los tipos de hogar y, tal como se ha evidenciado previamente (Smith; Jehlička, 2013), estas prácticas involucraron más verduras, frutas y hierbas que ganado o productos de origen animal. Igualmente, se evidenció cómo el intercambio de alimentos estaba menos generalizado que el autoabastecimiento; sin embargo, dicho intercambio era practicado por aproximadamente una cuarta parte de los participantes de este estudio, con mayores proporciones de participación para tipos de hogar $\mathrm{B}, \mathrm{Cy} \mathrm{D}$ que para el tipo A (este último integrado por agricultores generalmente más orientados al mercado).

Este estudio no puede confirmar la difusión del AIDE entre las clases sociales, lo que se observó en otros lugares (Smith et al., 2015), porque todos los sectores periurbanos de Sogamoso son principalmente poblados por hogares de bajos ingresos.

Los agricultores periurbanos de los cuatro tipos de hogares identificados en este estudio tenían una percepción general muy positiva del papel de la APU en 
Sogamoso. Los participantes destacaron la contribución positiva de la APU como fuente de ingresos, así como fuente de alimentos saludables y limpios (a pesar de los problemas con contaminación del agua informados por la Alcaldía de Sogamoso), lo que contribuyó a su seguridad alimentaria. Estos hallazgos se alinean con aquellos reportados en estudios anteriores sobre la APU, así como aquellos sobre la sostenibilidad silenciosa (Orsini et al., 2013; Poulsen et al., 2015; Smith; Jehlička, 2013;). Además, en línea con estudios anteriores del AIDE en Europa Central y Oriental (Jehlička et al., 2018), se ha encontrado que estas prácticas estaban asociadas con mayor seguridad de acceso a la tierra y bajo uso de productos químicos (Cuadro 1). En resumen, este estudio indica la existencia de una dinámica red social de intercambio de alimentos y una fuerte tendencia a cultivar al menos parte del propio suministro de alimentos en el espacio periurbano de Sogamoso.

Esta investigación proporciona evidencia contundente que contrasta con los discursos dominantes de desarrollo urbano en esta ciudad (Feola et al., 2019), que han tendido a pasar por alto tal diversidad en la APU en su intento de retratar lo periurbano como un espacio vacío a la espera de un uso urbano productivo. Esta situación es coherente con los hallazgos de otros estudios, que encontraron desajustes similares entre las representaciones discursivas homogeneizadoras y las diversas realidades de la APU en el territorio (Ives; Kendal, 2013; Mackay, 2018; Mougeot, 2005). Además, estos resultados ofrecen una base para imaginarios alternativos que propendan por la persistencia de la APU en Sogamoso.

A pesar de la práctica generalizada del AIDE, se han encontrado varias dificultades, la más citada de las cuales fue la presión sobre las tierras agrícolas, particularmente entre los agricultores más orientados al mercado (tipo A). Feola et al. (2019) han documentado en profundidad tales presiones sobre el uso de la tierra agrícola, que compite con la expansión de la ciudad en espacios periurbanos. Del mismo modo, la medida en que los agricultores periurbanos expresaron una percepción negativa de la agricultura por la ciudadanía y los bajos niveles de asistencia técnica y financiera también confirmaron los hallazgos de estudios anteriores (Feola, 2017). Estas últimas cuestiones están inscritas en las dificultades de un sector agrícola lento y una reestructuración más general de este sector en Colombia, que apunta hacia la apertura internacional y su supuesta modernización a través de la competencia comercial (Feola et al., 2015; Marín-Usuga; Arnalte-Alegre; Casamitjana-Causa; Loaiza-Usuga, 2016). Estos hallazgos muestran cómo, incluso cuando la APU se sitúa en el espacio periurbano específico de Sogamoso, depende y se halla integrada a procesos socioculturales y económicos más amplios y de múltiples niveles que solamente se rigen y gobiernan parcialmente desde lo local. 


\section{Contribución a la literatura sobre agricultura periurbana y sostenibilidad silenciosa}

Este estudio expande tanto la literatura sobre APU como aquella que trata la sostenibilidad silenciosa en al menos tres formas. Primero, conecta esta literatura, por primera vez, con debates actuales sobre los impactos y la sostenibilidad de la APU. En el mismo sentido, muestra cómo la naturaleza dinámica, híbrida, multifuncional y compleja de los espacios periurbanos (Lerner; Eakin, 2011; Marshall et al., 2009; Pérez-Martínez, 2016) facilita la discusión de las prácticas de cultivo de alimentos y las visiones de la agricultura en tales entornos (Feola et al., 2019; Mackay, 2018; Mougeot, 2005). Además, muchos impactos de la APU son intangibles: su contribución a las identidades culturales (Mougeot, 2005; Rodríguez-Alonso; Simón-Tenorio, 2016), así como su papel en el mantenimiento de las interconexiones de la diversidad biológica y cultural (Galluzzi et al., 2010; Lin et al., 2015). Específicamente, este estudio muestra que la perspectiva de la sostenibilidad silenciosa aplicada a los espacios periurbanos ayuda a identificar formas de APU que, de otro modo, estarían ocultas, y destaca el papel del AIDE en el fortalecimiento de la seguridad alimentaria local y del tejido social de las comunidades locales que viven en la periferia urbana, contribuyendo así a su sentido de propósito y resiliencia (Jehlička et al., 2018; Pungas, 2019; Smith; Jehlička, 2013).

Segundo, esta investigación amplía la literatura de sostenibilidad silenciosa al aplicar esta perspectiva a un contexto geográfico y un estado sociopolítico -una ciudad provincial en un país en desarrollo en América Latina- que difiere en muchos aspectos de los contextos de Europa Central y Oriental, donde originalmente se estudió la sostenibilidad silenciosa. Este estudio no solo muestra que el AIDE se practica silenciosamente en otros contextos geográficos, sino que también indica, de manera más interesante, cómo las prácticas generalizadas de sostenibilidad silenciosa no solo deben reconocerse en sociedades que están en transición desde economías de planificación centralizada a economías orientadas al mercado, sino en muchos lugares del Sur Global, donde las personas se enfrentan a imperativos de desarrollo difícilmente eludible, a menudo impuestos externamente, destinados a occidentalizar la sociedad (Escobar, 1995; Mignolo, 2007).

En contextos como el de Sogamoso y, en general, Colombia, donde los discursos desarrollistas influyen considerablemente sobre las estrategias nacionales y locales de gestión ambiental en muchos sectores (Cárdenas; Rodríguez, 2013; Carrizosa-Umaña, 2008), la búsqueda del desarrollo amenaza con barrer modos existentes de organizar la vida cotidiana, los cuales tienen sentido social, funcionan bien y existen debajo del radar de estructuras sociopolíticas más grandes, lo que pone en peligro la reproducción de significados comunes y redes sociales. Por lo tanto, reve- 
lar prácticas de sostenibilidad silenciosa contribuye a la apreciación de los modos de vida existentes, así como a la refutación de los discursos del subdesarrollo y el vaciamiento del espacio empleado por aquellos que presionan por la apropiación de la tierra para modelos de desarrollo moderno excluyentes, urbanos y occidentales (Feola et al., 2019). Desde este punto de vista, al igual que los agricultores de Europa Central y Oriental, los agricultores periurbanos de Sogamoso pueden ser vistos como pioneros de prácticas sostenibles preexistentes que están para ser visibilizadas y promovidas en lugar de ser reliquias de un pasado para olvidar, dando paso a formas de vida modernas, urbanas y desarrolladas (De Hoop; Jehlička, 2017).

En tercer lugar, con base en los puntos anteriores, este estudio proporciona nuevos argumentos para la protección y promoción de la APU, particularmente en el Sur Global. Aunque la agricultura urbana a menudo es medida en términos de productividad, tanto por quienes se oponen como por los que la defienden (Neilson; Rickards, 2017), este estudio proporciona evidencia en apoyo a los impactos benéficos, no económicos y de difícil cuantificación, de la APU en la construcción del sentido de propósito, tejido social y resiliencia de las comunidades locales. Además -y lo que es más importante-, este estudio hace evidente cómo estos logros no son el resultado del activismo ambiental o agrícola o de intervenciones públicas, sino que surgen de prácticas normales generalizadas en las comunidades locales. Mientras que las iniciativas gubernamentales o no gubernamentales de promoción de la APU, así como los proyectos cívicos y las huertas comunitarias, se han asociado con el fortalecimiento de comunidades (Poulsen, 2017), la perspectiva de sostenibilidad silenciosa revela casos en los cuales la construcción comunitaria no es un objetivo declarado de una iniciativa agrícola, tampoco el resultado de iniciativas colectivas emergentes, sino, más bien, un efecto positivo, aunque secundario, de las prácticas generalizadas del AIDE. Es importante resaltar que dichas prácticas no requieren dirección, configuración u organización o gobernanza ad hoc, pero pueden necesitar el apoyo oficial y la gobernanza para protegerlas contra quienes buscan erradicarlas al sustituirlas por formas de desarrollo de tipo monetario.

\section{Apoyar a la agricultura periurbana y la sostenibilidad silenciosa}

Los hallazgos de este estudio exigen una reflexión sobre los modelos, políticas e intervenciones de desarrollo urbano que pueden facilitar la APU. Se ha demostrado que la agricultura periurbana es robusta y adaptable en varios contextos (Clark; Jackson-Smith; Sharp; Munroe, 2007; Elhadary; Samat; Obeng-Odoom, 2013; Lerner; Eakin, 2011); sin embargo, la gobernanza es un factor crítico en su persistencia y logros (Feola et al., 2019; Prové; Dessein; De Krom, 2016; Tacoli, 2003). Proteger a la APU implica proporcionar orientación al desarrollo urbano más que detenerlo 
(Ligrone-Fernández, 2016). De acuerdo con Davies et al. (2017), se puede sugerir que dicha orientación puede ser útilmente informada para una mejor comprensión de los "objetos, espacios y habilidades" de la APU y el AIDE; es decir, cómo los agricultores periurbanos los desempeñan.

Está más allá del alcance de este estudio proporcionar recomendaciones completas de políticas públicas, cuya formulación requeriría una base empírica más extensa, así como procesos socialmente integrados de deliberación y toma de decisiones. Sin embargo, se pueden compartir algunas reflexiones para informar posibles líneas de intervención social y política. Por ejemplo, el acceso a algunos de los objetos de la APU, como equipos y semillas, podría apoyarse a través de incentivos fiscales (Smith; Jehlička, 2013), que pueden facilitar la participación en estas prácticas. La protección legal de los sistemas informales de intercambio de semillas, que es un tema controvertido en Colombia (Gutiérrez-Escobar; Fitting, 2016), permitiría la circulación de variedades nativas y no nativas a través de huertas y granjas urbanas.

Los espacios para la producción de alimentos en las ciudades colombianas han sido tradicionalmente jardines traseros (solares, patios) y lotes baldíos (Molina, 2015). Desarrollos urbanos recientes, como los bloques de apartamentos y los conjuntos cerrados que han aparecido en Sogamoso, impiden la producción de alimentos por parte de los residentes (Feola et al., 2019). La protección, expansión y apoyo de espacios para la APU implican la defensa de espacios urbanos aún no construidos, así como la promoción de la planificación de espacios públicos y modelos de vivienda privada que dejen lugar para huertas productivas y espacios agrícolas para individuos y comunidades (Ayambire et al., 2019; Smith; Jehlička, 2013).

Como es el caso en la mayoría de las ciudades colombianas, el flujo de migrantes rurales en Sogamoso hace que las habilidades de producción de alimentos estén disponibles, particularmente en espacios periurbanos; sin embargo, la estigmatización del campesinado y del mundo rural y la conveniencia de la vida moderna a menudo motivan a los ciudadanos a desaprender sus habilidades de producción de alimentos (Feola, 2017). La reevaluación de las habilidades tradicionales de producción de alimentos podría desempeñar un papel en la lucha contra esta tendencia, por ejemplo, a través de los medios de comunicación (Smith; Jehlička, 2013), pero también mediante un movimiento social más amplio que muestre las posibilidades de tales habilidades y la promoción de su reproducción. Los cursos de capacitación ya existentes pueden complementar lo anterior, especialmente para aquellos que no tienen experiencia en agricultura o acceso al desarrollo de habilidades de producción de alimentos a través de su red social; no obstante, estos cursos están sujetos a recortes y a menudo están desconectados de las necesidades locales. 


\section{Conclusión}

En ciudades como Sogamoso, en el Sur Global, la APU puede estar asociada no solo con la producción orientada al mercado, o programas cívicos o sociales diseñados por organizaciones gubernamentales o no gubernamentales, sino también con prácticas de AIDE normales, cultural y socialmente arraigadas.

Es mucho lo que está en juego en el desarrollo urbano: la expansión del entorno urbano construido hacia el espacio periurbano no intercambia tierras vacías e improductivas por viviendas y desarrollo modernos, sino que impulsa la pérdida de la APU y del AIDE como fuentes significativas desde el punto de vista social y cultural, de cohesión social, ingresos alternativos, seguridad alimentaria y resiliencia social. En lugar de alentar la complacencia y una mayor retirada de la provisión de integración social y resiliencia por parte del sector público, este estudio muestra que hay un margen para facilitar y apoyar las prácticas ya existentes. Sin embargo, para que esto suceda de manera coherente con los significados sociales y culturales vinculados a esas prácticas, es necesario reconsiderar las visiones del desarrollo urbano, lo que incluye una reevaluación de la compatibilidad de la expansión urbana y otros objetivos sociales como la seguridad alimentaria y la integración social.

En Colombia, donde la mayoría de las ciudades medianas y grandes han recibido flujos de migrantes voluntarios y ciudadanos desplazados de las zonas rurales por la fuerza, los cuales a menudo se han establecido en los espacios periurbanos de esas ciudades, puede haber una oportunidad infravalorada para buscar visiones alternativas de desarrollo. El pasado agrario no muy lejano encarnado en estas poblaciones migrantes, y la necesidad de promover la integración social en las franjas periurbanas hacen que las prácticas de sostenibilidad silenciosa ya existentes sean una fuerza potencialmente poderosa para fortalecer el sentido del propósito y el tejido social.

En América Latina y otras partes del Sur Global, donde las ciudades enfrentan la necesidad de crear resiliencia al cambio ambiental, el reconocimiento, la protección y el apoyo a las prácticas de sostenibilidad silenciosa como la APU representan una forma de intervención culturalmente sensible y endógena que deja espacios abiertos para visiones plurales del desarrollo urbano, lo que puede ser complementario y, en cierta medida, alternativo a otras intervenciones exógenas, privadas o públicas.

\section{Agradecimientos}

Los autores agradecen sinceramente a los participantes en la investigación y a los entrevistadores que administraron la encuesta. También agradecen a Evelien de Hoop por sus estimulantes comentarios sobre una versión anterior de este manuscrito, 
y a Marcus Ton por su apoyo cartográfico. Esta investigación fue financiada por la Royal Geographical Society (con IBG) a través de la Environment and Sustainability Research Grant núm. 17/o1.

\section{Referencias}

Alcaldía de Sogamoso (2013). Componente de clasificación del suelo, modelo de ocupacióny norma. Sogamoso: Alcaldía de Sogamoso.

Alcaldía de Sogamoso (2016). Plan de Desarrollo 2016-2019: Sogamoso incluyente. Sogamoso: Alcaldía de Sogamoso.

Arias-Arbeláez, Fabio Alberto; Vargas, Gloria María (2010). Instituciones, gobernanza y sustentabilidad en la política colombiana de ordenamiento territorial municipal. Sociedady Economía, 19, 279-304. Recuperado de http://www.scielo.org.co/pdf/soec/n19/n19a14.pdf

Ayambire, Raphael Anammasiya; Amponsah, Owusu; Peprah, Charles; Takyi, Stephen Appiah (2019). A Review of Practices for Sustaining Urban and Peri-Urban Agriculture: Implications for Land Use Planning in Rapidly Urbanising Ghanaian Cities. Land Use Policy, 84, 260-277. https://doi.org/10.1016/j.landusepol.2019.03.004

Cámara de Comercio de Sogamoso (2017). Estudio de percepción económica de Sogamoso. Sogamoso: Cámara de Comercio.

Cantor, Kelly-M. (2010). Agricultura urbana: elementos valorativos sobre su sostenibilidad. Cuadernos de Desarrollo Rural,7, 61-87. Recuperado de http://www.scielo.org.co/pdf/cudr/ v7n65/v7n65a04.pdf

Cárdenas, Martha; Rodríguez, Manuel (eds.) (2013). Desarrollo económico y adaptación al cambio climático. Bogotá: Fescol/Foro Nacional Ambiental.

Carrizosa-Umaña, Julio (2008). Prólogo. Instituciones y ambiente gobernabilidad. En Instituciones y medio ambiente en Colombia (pp. 1-64). Bogotá: Friedrich Ebert Stiftung/ Foro Nacional Ambiental.

Clark, Jill K.; Jackson-Smith, Douglas; Sharp, Jeff S.; Munroe, Darla K. (septiembre, 2007). The Geography of US Periurban Agricultural Adaptation. Trabajo presentado en TransAtlantic Land Use Conference, Washington DC, Estados Unidos.

Contesse, Maria; Van Vliet, Bas J. M.; Lenhart, Jennifer (2018). Is Urban Agriculture Urban Green Space? A Comparison of Policy Arrangements for Urban Green Space and Urban Agriculture in Santiago de Chile. Land Use Policy, 71, 566-577. https://doi.org/10.1016/j. landusepol.2017.11.006 
Davies, Anna R.; Edwards, Ferne; Marovelli, Brigida; Morrow, Oona; Rut, Monika; Weymes, Marion (2017). Creative Construction: Crafting, Negotiating and Performing Urban Food Sharing Landscapes. Area, 49, 510-518. https://doi.org/10.1111/area.12340

De Hoop, Eveline; Jehlička, Petr (2017). Reluctant Pioneers in the European Periphery? Environmental Activism, Food Consumption and "Growing your Own". Local Environment, 22, 809-824. https://doi.org/10.108o/13549839.2017.128916o

De Zeeuw, Henk (octubre, 2004). The Development of Urban Agriculture; Some Lessons Learnt. Trabajo presentado en Urban Agriculture, Agro-Tourism and City Region Development Congress, Beijing, China.

De Zeeuw, Henk; Dubbeling, Marielle (septeimbre, 2009). Cities, Food and Agriculture: Challenges and the Way Forward. Trabajo presentado en Agriculture, Food and Cities, Roma, Italia.

Departamento Administrativo Nacional de Estadística (2018). Censo Nacional de Poblacióny Vivienda 2018: información técnica. Bogotá: DANE.

Departamento Nacional de Planeación (2016). POT Modernos. Bogotá: DNP.

Drechsel, Pay; Keraita, Bernard (2014). Irrigated Urban Vegetable Production in Ghana: Characteristics, Benefits and Risk Mitigation. Colombo: International Water Management Institute. Recuperado de https://www.iwmi.cgiar.org/Publications/Books/PDF/irrigated_ urban_vegetable_production_in_ghana.pdf

Eigenbrod, Christine; Gruda, Nazim (2015). Urban Vegetable for Food Security in Cities. A Review. Agronomy for Sustainable Development, 35, 483-498. https://doi.org/10.1007/ S13593-014-0273-y

Elhadary, Yasin Abdalla Eltayeb; Samat, Narimah; Obeng-Odoom, Frankiln (2013). Development at the Peri-Urban Area and its Impact on Agricultural Activities: An Example from the Seberang Perai Region, Penang State, Malaysia. Agroecology and Sustainable Food Systems, 37, 834-856. https://doi.org/10.1080/21683565.2013.797950

Escobar, Arturo (1995). Encountering Development. The Making and Unmaking of the Third World. Princeton: Princeton University Press.

Feola, Giuseppe (2017). Adaptive Institutions? Peasant Institutions and Natural Models Facing Climatic and Economic Changes in the Colombian Andes. Journal of Rural Studies, 49, 117-127. https://doi.org/10.1016/j.jrurstud.2016.10.007

Feola, Giuseppe; Agudelo-Vanegas, Luis Alfonse; Contesse-Bamón, Bernardita Paz (2015). Colombian Agriculture under Multiple Exposures: A Review and Research Agenda. Climate and Development, 7, 278-292. https://doi.org/10.108o/17565529.2014.934776 
Feola, Giuseppe; Sahakian, Marlyne; Binder, Claudia Rebeca (2020). Sustainability Assessment of Urban Agriculture. En Sustainability Assessment of Urban Systems (pp.417-437). Cambridge: Cambridge University Press.

Feola, Giuseppe; Suzunaga, Jaime; Soler, Jenny; Goodman, Michael Kenneth (2019). Ordinary Land Grabbing in Periurban Spaces: Land Conflicts and Governance in a Small Colombian City. Geoforum, 105, 145-157. https://doi.org/10.1016/j.geoforum.2019.05.018

Galluzzi, Gea; Eyzaguirre, Pablo; Negri, Valeria (2010). Home Gardens: Neglected Hotspots of Agrobiodiversity and Cultural Diversity. Biodiversity and Conservation, 19, 3635-3654. https://doi.org/10.1007/s10531-010-9919-5

Goldstein, Benjamin P.; Hauschild, Michael Z.; Fernández, John E.; Birkved, Morton (2017). Contributions of Local Farming to Urban Sustainability in the Northeast United States. Environmental Science and Technology, 51, 7340-7349. https://doi.org/10.1021/acs. est.7bo1011

Gutiérrez-Escobar, Laura; Fitting, Elizabeth (2016). The Red de Semillas Libres: Contesting Biohegemony in Colombia: Contesting Biohegemony in Colombia. Journal of Agrarian Change, 16, 711-719. https://doi.org/10.1111/joac.12161

Infoagro Systems (14 de marzo de 2012). Agricultura de guerrilla. InfoAgro. Recuperado de https://www.infoagro.com/noticias/2012/3/19761_agricultura_guerrilla.asp

Ives, Christopher D.; Kendal, Dave (2013). Values and Attitudes of the Urban Public Towards Peri-Urban Agricultural Land. Land Use Policy, 34, 80-90. https://doi.org/10.1016/j. landusepol.2013.02.003

Jehlička, Petr; Daněk, Petr (2017). Rendering the Actually Existing Sharing Economy Visible: Home-Grown Food and the Pleasure of Sharing. Sociologia Ruralis, 57, 274-296. https:// doi.org/10.1111/soru.1216o

Jehlička, Petr; Daněk, Petr; Vávra, Jan (2018). Rethinking Resilience: Home Gardening, Food Sharing and Everyday Resistance. Canadian Journal of Development Studies, 4O(4), 511-527. https://doi.org/10.1080/02255189.2018.1498325

Lerner, Amy M.; Eakin, Hallie (2011). An Obsolete Dichotomy? Rethinking the Rural-Urban Interface in Terms of Food Security and Production in the Global South. Geographical Journal, 177, 311-320. https://doi.org/10.1111/j.1475-4959.2010.00394.x

Ligrone-Fernández, Pablo Alfredo (2016). Manejo de bordes de crecimiento urbano en Uruguay. Bitácora Urbano-Territorial, 26, 73-82. https://doi.org/10.15446/bitacora.v26n1.43182

Lin, Brenda B.; Philpott, Stacy M.; Jha, Shalene (2015). The Future of Urban Agriculture and Biodiversity Ecosystem Services: Challenges and Next Steps. Basic and Applied Ecology, 16, 189-201. https://doi.org/10.1016/j.baae.2015.01.005 
Mackay, Heather (2018). Mapping and Characterising the Urban Agricultural Landscape of Two Intermediate-Sized Ghanaian Cities. Land Use Policy, 7o, 182-197. https://doi.org/10.1016/j. landusepol.2017.10.031

Madaleno, Isabel Maria; Gurovich, Alberto (2004). "Urban Versus Rural” no Longer Matches Reality: An Early Public Agro-Residential Development in Periurban Santiago, Chile. Cities, 21, 513-526. https://doi.org/10.1016/j.cities.2004.08.001

Marín-Usuga, Matin René; Arnalte-Alegre, Eladio; Casamitjana Causa, Maria; Loaiza-Usuga, Juan Carlos (2016). Policies of Agricultural Modernization and Rural Development in Colombia (1996-2008). Revista EIA, 13, 99-117. https://doi.org/10.14508/reia.2016.13.25.99-117

Marshall, Fiona; Waldman, Linda; MacGregor, Hayley; Mehta, Lyla; Randhawa, Pritpal (2009). On the Edge of Sustainability: Perspectives on Peri-Urban Dynamics (STEPS Working Paper 35). Brighton: Steps Centre. Recuperado de https://www.researchgate. net/publication/303460284_On_the_edge_of_sustainability_Perspectives_on_peri-urban_ dynamics

Mehta, Lyla; Karpouzoglou, Timothy (2015). Limits of Policy and Planning in Peri-Urban Waterscapes: The Case of Ghaziabad, Delhi, India. Habitat International, 48, 159-168. https://doi.org/10.1016/j.habitatint.2015.03.008

Méndez, Marlon; Ramírez, Luz; Alzate, Alejandro (2005). La práctica de la agricultura urbana como expresión de emergencia de nuevas ruralidades: reflexiones en torno a la evidencia empírica. Cuadernos de Desarrollo Rural, 55, 51-70. Recuperado de https://revistas.javeriana. edu.co/index.php/desarrolloRural/article/view/1243

Mignolo, Walter D. (2007). Delinking. Cultural Studies, 21(2), 449-514. http://dx.doi. org/10.1080/09502380601162647

Molina, Diego (2015). Losárbolessetoman la ciudad. El proceso demodernizaciónyla transformación del paisaje en Medellín, 1890-195o. Medellín: Universidad de Antioquia.

Mougeot, Luc J. A. (2005). Agropolis: The Social, Political and Environmental Dimensions of Urban Agriculture. London: IDRC/Earthscan. Recuperado de https://idl-bnc-idrc.dspacedirect. org/bitstream/handle/10625/28341/IDL-28341.pdf? sequence=47\&isAllowed $=y$

Nadal, Ana; Cerón-Palma, Ileana; García-Gómez, Carmen; Pérez-Sánchez, Maria; RodríguezLabajos, Beatriz; Cuerva, Eva; Josa, Alejandro; Rieradevall, Joan (2018). Social Perception of Urban Agriculture in Latin-America. A Case Study in Mexican Social Housing. Land Use Policy, 76, 719-734. https://doi.org/10.1016/j.landusepol.2018.02.055

Neilson, Chenae; Rickards, Lauren (2017). The Relational Character of Urban Agriculture: Competing Perspectives on Land, Food, People, Agriculture and the City. Geographical Journal, 183, 295-306. https://doi.org/10.1111/geoj.12188 
Orsini, Francesco; Kahane, Remi; Nono-Womdim, Remi; Gianquinto, Giorgio (2013). Urban Agriculture in the Developing World: A Review. Agronomy for Sustainainable Development, 33, 695-720. https://doi.org/10.1007/s13593-013-0143-z

Parra-Peña, Rafael Isidro; Ordóñez, Liliana; Acosta, Camilo (2012). Políticas que cierran brechas entre lo urbano y lo rural en Colombia. CIAT Políticas en sintesis, 7. Recuperado de https:// core.ac.uk/reader/132667856

Pearson, Leonie J.; Pearson, Linda; Pearson, Craig J. (2010). Sustainable Urban Agriculture: Stocktake and Opportunities. International Journal of Agricultural Sustainability, 8(1), 7-19. https://doi.org/10.3763/ijas.2009.0468

Pérez-Martínez, Manuel Enrique (2016). Las territorialidades urbano-rurales contemporáneas: un debate epistémico y metodológico para su abordaje. Bitácora Urbano-Territorial, 26, 103. https://doi.org/10.15446/bitacora.v26n2.56216

Poulsen, Melissa N. (2017). Cultivating Citizenship, Equity, and Social Inclusion? Putting Civic Agriculture into Practice through Urban Farming. Agriculture and Human Values, 34(1), 135-148. https://doi.org/10.1007/s10460-016-9699-y

Poulsen, Melissa N.; McNab, Philip R.; Clayton, Megan L.; Neff, Roni A. (2015). A Systematic Review of Urban Agriculture and Food Security Impacts in Low-Income Countries. Food Policy, 55, 131-146. https://doi.org/10.1016/j.foodpol.2015.07.002

Prové, Charlotte; Dessein, Joost; De Krom, Michiel (2016). Taking Context into Account in Urban Agriculture Governance: Case Studies of Warsaw (Poland) and Ghent (Belgium). Land Use Policy, 56, 16-26. https://doi.org/10.1016/j.landusepol.2016.04.025

Pungas, Lilian (2019). Food Self-Provisioning as an Answer to the Metabolic Rift: The Case of 'Dacha Resilience' in Estonia. Journal of Rural Studies, 68, 75-86. https://doi.org/10.1016/j. jrurstud.2019.02.010

Rodríguez-Alonso, Raquel; Simón-Tenorio, Susana (2016). Oportunidades en la planificación del espacio periurbano. Bitácora Urbano-Territorial, 26, 63-72. https://doi.org/10.15446/ bitacora.v26n1.43164

Sahakian, Marlyne; Saloma, Czarina; Erkman, Suren (2016). Food Consumption in the City: Practices and Patterns in Urban Asia and the Pacific. Abingdon: Routledge.

Smith, Joe; Jehlička, Petr (2013). Quiet Sustainability: Fertile Lessons from Europe's Productive Gardeners. Journal of Rural Studies, 32, 148-157. https://doi.org/10.1016/j. jrurstud.2013.05.002

Smith, Joe; Kostelecký, Tomáš; Jehlička, Petr (2015). Quietly does it: Questioning Assumptions about Class, Sustainability and Consumption. Geoforum, 67, 223-232. https://doi. org/10.1016/j.geoforum.2015.03.017 
Tacoli, Cecilia (2003). The Links between Urban and Rural Development. Environment and Urbanization, 15(1), 3-12. https://doi.org/10.1177/095624780301500111

Van Veenhuizen, René (2006). Cities Farming for the Future. Urban Agriculture for Green and Productive Cities. Ottawa: IDRC/IIRR/RUAF Foundation.

Vávra, Jan; Daněk, Petr; Jehlička, Petr (2018). What is the Contribution of Food Self-Provisioning towards Environmental Sustainability? A Case Study of Active Gardeners. Journal of Cleaner Production, 185, 1015-1023. https://doi.org/10.1016/j.jclepro.2018.02.261

Warren, Emily; Hawkesworth, Sophie; Knai, Cécile (2015). Investigating the Association between Urban Agriculture and Food Security, Dietary Diversity, and Nutritional Status: A Systematic Literature Review. Food Policy, 53, 54-66. https://doi.org/10.1016/j. foodpol.2015.03.004

Zezza, Alberto; Tasciotti, Luca (2010). Urban Agriculture, Poverty, and Food Security: Empirical Evidence from a Sample of Developing Countries. Food Policy, 35, 265-273. https://doi. org/10.1016/j.foodpol.2010.04.007

Zoomers, Annelies; Van Noorloos, Femke; Otsuki, Kei; Steel, Griet; Van Westen, Guus (2017). The Rush for Land in an Urbanizing World: From Land Grabbing toward Developing Safe, Resilient, and Sustainable Cities and Landscapes. World Development, 92, 242-252. https:// doi.org/10.1016/j.worlddev.2016.11.016 